\title{
Gümüşhane İli Yerel Fasulye Genotiplerinin Morfolojik ve Tarımsal Özellikler Yönünden Karakterizasyonu Üzerine Bir Ön Çalışma
}

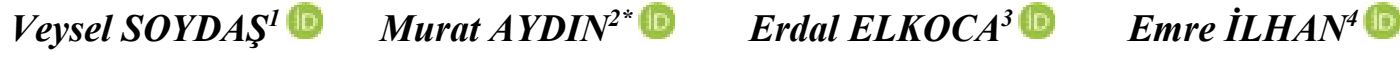 \\ ${ }^{1}$ Atatürk Üniversitesi Ziraat Fakültesi Tarla Bitkileri Bölümü, Erzurum/TURKEY \\ ${ }^{2}$ Atatürk Üniversitesi Ziraat Fakültesi Tarımsal Biyoteknoloji Bölümü, Erzurum/TURKEY \\ ${ }^{3}$ A ğrı İbrahim Çeçen Üniversitesi Meslek Yüksek Okulu Bitkisel ve Hayvansal Üretim Bölümü, Ăgrı/TURKEY \\ ${ }^{4}$ Erzurum Teknik Üniversitesi Fen Fakültesi Moleküler Biyoloji ve Genetik Bölümü, Erzurum/TURKEY

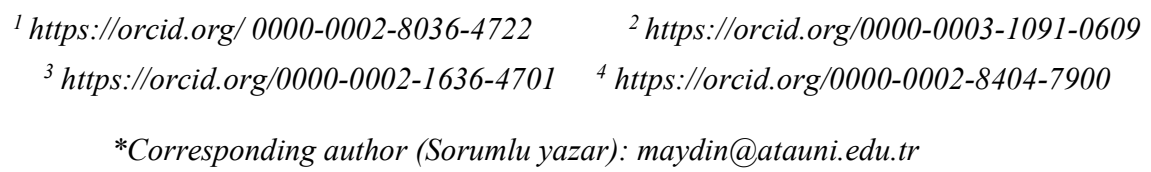 \\ Received (Geliş tarihi): 12.02.2021 Accepted (Kabul tarihi): 29.07.2021
}

ÖZ: Bu çalışmada, Gümüşhane ilinin bütün ilçelerindeki yerel fasulye (Phaseolus vulgaris L.) genotipleri toplanarak tanımlamalarının yapılması ve üstün özelliğe sahip olan genotipler belirlenerek ileride yapılacak ıslah ve seleksiyon çalışmaları için çekirdek koleksiyon oluşturulması amaçlanmıştır. Gümüşhane merkez ve ilçeler, 2014 yılı hasat döneminde gezilerek 49 fasulye genotipine ait tohumlar toplanmış ve toplanan genotipler 2015 yllında Gümüşhane-Kelkit Öbektaş beldesinde Şansa Bağll Tam Bloklar Deneme Deseninde 3 tekrarlamalı olarak morfolojik ve tarımsal özellikler yönünden denemeye alınmıştır. Genotiplerin morfolojik karakterizasyonu IPGRI ve EU-CPVO tarafindan geliştirilen çeşit değerlendirme kriterlerine göre yapılmıștır. Ayrıca, çıkıştan hasada kadarki dönemde, fenoloji, verim ve verim unsurları ile ilgili gözlem ve ölçümler yapılmıştır. Böylece genotiplerin değerlendirilmesinde 30 adet morfolojik ve 9 adet tarımsal özellik dikkate alınmıştır. Araştırma sonucunda, incelenen morfolojik özelliklerden 20 tanesinde genotiplerin değişkenlik gösterdiği ve tarımsal özellikler bakımından da genotipler arasında önemli farkların bulunduğu belirlenmiştir. Genotipler morfolojik ve tarımsal özellikler bakımından ayrı ayrı kümeleme analizine tabi tutulmuş ve genotipler morfolojik olarak üç, tarımsal özellikler bakımından ise dört ana grupta kümelenmiştir. Sonuç olarak, tarımsal özellikler bakımından yapılan sınıflandırmada yüksek verimli ve erkenci genotiplerin yer aldı ̆̆ Grup B ile tarla koşullarında seleksiyon çalışmalarına devam edilmesine karar verilmiştir.

Anahtar kelimeler: Fasulye, Phaseolus vulgaris L., karakterizasyon, seleksiyon, kümeleme analizi.

\section{A Preliminary Study on the Characterization of Common Bean Landraces in Gümüşhane in Terms of Morphological and Agricultural Characteristics}

\begin{abstract}
In this study, local bean (Phaseolus vulgaris L.) genotypes in all districts of Gümüşhane were collected and characterized with the aim of creating a core collection for future breeding and selection studies by determining genotypes with superior features. Forty-nine common bean genotypes were collected by visiting central Gümüşhane and its districts during the harvest period in 2014. These genotypes were investigated for morphological and agricultural characteristics in three randomized complete blocks in Öbektaş town of Gümüshane-Kelkit in the 2015 crop season. Morphological characterization of genotypes was made according to the variety evaluation criteria developed by IPGRI and EU-CPVO. In addition, in the period between emergence and harvest, observations and measurements were made on phenology, yield and yield components. Thus, 30 morphological and 9 agricultural characteristics were taken into account in the evaluation of genotypes. Results showed that bean genotypes varied in 20 of the morphological traits examined and that there were important differences among genotypes in terms of agricultural characteristics. Genotypes were subjected to cluster analysis separately in terms of morphological and agricultural characteristics and were clustered into three main groups based on morphological characteristics and four main groups based on agricultural characteristics. It was decided to continue selection studies under field conditions with Group B, which includes high yielding and early maturing genotypes.
\end{abstract}

Keywords: Bean, Phaseolus vulgaris L., characterization, selection, cluster analysis. 


\section{GİRIŞ}

Kuru fasulye (Phaseolus vulgaris L.), ekim alanı (34,5 milyon ha) ve üretim miktarı (30,4 milyon ton) bakımından Dünya'da yemeklik tane baklagiller içerisinde ilk sırada yer almaktadır. Ülkemizde ise 848 bin da ekim alanı ve 220 bin ton üretim miktarı ile nohut ve mercimekten sonra en çok üretilen yemeklik baklagildir (Anonymous, 2019). Gümüşhane'nin kuru fasulye ekim alanı 17,1 bin da olup üretim miktarı 3,3 bin tondur (Anonim, 2019a). Bu veri, Gümüşhane'nin ülkesel kuru fasulye ekim alanı içerisindeki payının \%2,0, üretimdeki payının ise $\% 1,5$ olduğunu ifade etmektedir. İlin ülkesel kuru fasulye üretimindeki payının ekim alanı içerisindeki payı ile orantısız oluşu, ildeki birim alan kuru fasulye veriminin $(193,0 \mathrm{~kg} / \mathrm{da})$ ülke ortalamasından $(259,5 \mathrm{~kg} / \mathrm{da})$ düşük olmasından kaynaklanmaktadır. Ülkemize 1750'li yılların ortasında girdiği tahmin edilen fasulye, ülkemizin neredeyse her yerine iyi adapte olmuş ve geniş bir varyasyon göstermiştir (Sözen, 2006).

Ülkemizin sahip olduğu ekolojik koşullardaki çeşitlilik, fasulye genotipleri üzerinde etkili olmuş ve zaman içerisinde farklı yöresel fasulye genotip/ ekotipleri ortaya çıkmıştır. Bunun bir sonucu olarak, fasulye açısından ülkemizin pek çok yöresi, 1slah ve seleksiyon çalışmalarına olanak sağlayacak ölçüde geniş bir genetik varyasyona sahip bulunmaktadır (Şehirali ve ark., 2005; Karataş ve ark., 2017). Bu nedenle ülkemizdeki yerel fasulye gen kaynaklarının taranması ve mevcut genetik potansiyelin ortaya çıkarılması büyük önem taşımaktadır (Fita ve ark., 2015; Karataş ve ark., 2017).

Karakterizasyon, bitki gen kaynakları içindeki genetik çeşitliliği ortaya çıkarmakta (Bode ve ark., 2013), bu nedenle bitki gen kaynaklarının karakterizasyonu yapilarak mevcut varyasyonun ortaya koyulması ve dağılış durumlarının tespit edilmesi, 1slah programlarının uygulanmasında yol gösterici olmaktadır (Bliss, 1980; Karataş ve ark., 2017). Bitki gen kaynaklarının karakterizasyonunda, morfolojik ve agronomik gözlem ve ölçümler bitki ıslahçıları tarafından yaygın olarak kullanılmaktadır (Martins ve ark., 2006; Kantar ve ark., 2010; Stoilova ve ark., 2013).
Genotiplerin çiçek, meyve, yaprak, dal, tohum gibi morfolojik; çıkış, çiçeklenme ve olgunlaşma süresi gibi fenolojik ve bitki boyu, dal sayısı, biyolojik verim, tane verimi ve hasat indeksi gibi tarımsal özelliklerinin belirlenmesi ıslahçıların çalışacakları materyali tanımaları açısından oldukça önemlidir (Kantar ve ark., 2010; Madakbaş ve Ergin, 2011). Günümüzde pek çok bitki türünde genotipler toplanmakta, tanımlamaları yapılmakta ve tanımlamalar sonucunda benzer olanlar elemine edilerek çekirdek koleksiyonlar oluşturulmaktadır. $\mathrm{Bu}$ şekilde çeşitli özellikler yönünden karakterize edilmiş materyalle çalışmak ıslahçıya zaman ve işgücü yönünden büyük tasarruf sağlamakta ve yeni çeşitlerin geliştirilmesine yönelik olarak başlatılacak 1slah çalışmalarında başarı şansını önemli seviyede arttırmaktadır (Açıkgöz, 2004).

Gümüşhane ili, fasulye gen kaynakları açısından oldukça geniş bir varyasyon göstermektedir. Doğu Karadeniz Bölgesi yerel fasulye populasyonlarının karakterizasyonunu yapmak ve morfolojik değişkenliğini belirlemek amacıyla Sözen ve ark. (2014) tarafindan bölgedeki 6 ilde yürütülen bir çalışmada, Gümüşhane ilinin yalnızca Merkez ve Kürtün ilçelerindeki populasyonlar toplanmıştır. Dolayısıyla bu güne kadar Gümüşhane ilinin tamamındaki fasulye gen kaynaklarının detaylı bir şekilde toplanıp değerlendirilmesine yönelik geniş kapsaml1 bir araştırma yürütülmemiştir. $\mathrm{Bu}$ eksikliği gidermeye yönelik olarak yürütülen bu çalışmada, Gümüşhane ilinin bütün ilçelerindeki fasulye genotipleri toplanarak tanımlamaları yapılmış ve üstün özelliğe sahip olanlar belirlenerek ileride yapilacak islah ve seleksiyon çalışmaları için çekirdek koleksiyon oluşturulması amaçlanmıştır.

\section{MATERYAL ve METOT}

\section{Araştırmada kullanılan fasulye genotipleri}

Araştırma kapsamındaki Gümüşhane merkez ve ilçeleri 2014 y1lı hasat döneminde ziyaret edilerek bitki tipi, hastalıklara tolerans, olgunlaşma ve verim gibi çeşitli özellikler yönünden ümitvar görülen toplam 49 kuru fasulye genotipi belirlenmiş ve bu çalışmanın materyalini oluşturmuştur (Çizelge 1). 
V. SOYDAS, M. AYDIN, E. ELKOCA, E. İLHAN: GÜMÜSHANE İLI YEREL FASULYE GENOTIPLERININ MORFOLOJIK VE TARIMSAL ÖZELLIKLER YÖNÜNDEN KARAKTERIZASYONU ÜZERINE BIR ÖN ÇALIŞMA

Çizelge 1. Fasulye genotiplerinin toplandığı yer ve lokasyon bilgileri.

Table 1 . Bean genotypes used in the study and their locations.

\begin{tabular}{llrrr}
\hline \multirow{2}{*}{$\begin{array}{l}\text { Genotip no. } \\
\text { Genotype no. }\end{array}$} & Toplandığı yer & \multicolumn{2}{c}{ Lokasyon (Location) } \\
\hline $7,22,28,32,39,40$ & Collection site & $\begin{array}{r}\text { Enlem } \\
\text { Latitude }\end{array}$ & $\begin{array}{r}\text { Boylam } \\
\text { Longitude }\end{array}$ & $\begin{array}{r}\text { Rakım (m) } \\
\text { Altitude }\end{array}$ \\
1,34 & Kelkit / Öbektaş Beldesi & 40,141 & 39,608 & 1.510 \\
33,42 & Kelkit / Dereyüzü & 40,126 & 39,373 & 1.365 \\
$11,31,48$ & Kelkit/ Çamur Köyü & 39,972 & 39,734 & 2.150 \\
20,24 & Kelkit/ Kaş Köyü & 40,127 & 39,516 & 1.450 \\
$6,13,16,49$ & Köse/ Merkez & 40,210 & 39,653 & 1.575 \\
35 & Köse/ Övünce & 40,157 & 39,658 & 1.580 \\
5,30 & Köse / Özbeyli & 40,197 & 39,706 & 1.600 \\
17,21 & Kürtün / Çayırçukur & 40,674 & 39,097 & 900 \\
3,36 & Kürtün / Demirciler & 40,650 & 39,112 & 1.000 \\
18 & Kürtün / Karaçukur & 40,672 & 39,139 & 673 \\
47 & Kürtün / Üçtaş & 40,760 & 38,951 & 660 \\
4,8 & Merkez / Bahçecik & 40,430 & 39,598 & 1.450 \\
$37,45,46$ & Merkez / Tekke & 40,418 & 39,585 & 1.230 \\
19,29 & Torul / Aksüt & 40,606 & 39,246 & 1.350 \\
$9,27,38$ & Torul / Altınpınar & 40,504 & 39,295 & 1.339 \\
14,25 & Torul / Harmancik & 40,537 & 39,313 & 1.250 \\
26,43 & Torul / Tokçam & 40,600 & 39,205 & 1.610 \\
$2,15,41$ & Şiran / Alı̧ç & 40,170 & 38,953 & 1.470 \\
$12,10,23$ & Şiran / Bahçeli & 40,251 & 39,031 & 1.590 \\
44 & Şiran / Bilgili & 40,209 & 39,103 & 1.460 \\
\hline & Şiran / Selimiye & 40,254 & 39,050 & 1.610 \\
\hline
\end{tabular}

Fasulye genotiplerinin toplandığı Gümüşhane ilinin bazı özellikleri

Gümüşhane, Doğu Karadeniz Bölgesinin iç k1sımlarında yer almakta olup, rakımı ortalama 1210 metredir. Kuzeyinde Trabzon, güneyinde Erzincan, doğusunda Bayburt, batısında Giresun illeri bulunur. Merkez, Kelkit, Şiran, Torul, Köse ve Kürtün olmak üzere 5 ilçesi bulunmaktadır (Şekil 1). Köse, Kelkit ve Şiran ilçeleri vadi özelliği gösterirken, Merkez, Torul ve Kürtün dağlık ve engebelidir. Tarımsal mekanizasyon ve teknoloji ilde gereği gibi kullanılmamakta, tarımsal üretim ise bölgede eskiden beri yetiștiriciliği yapılan türlerle yapılmaktadır.

\section{Araştırma yerinin toprak özellikleri}

Deneme, Gümüşhane ili Kelkit ilçesi Öbektaş Beldesi'nde kurulmuştur (Şekil 2). Deneme arazisi toprakları tınlı yapıda, hafif alkali, az kireçli ve tuz içeriği oldukça düşüktür. Organik madde içeriği
$(\% 0,14)$ çok az olan deneme arazisi yeterli seviyede fosfor ve yüksek miktarda potasyum içermektedir (Çizelge 2).

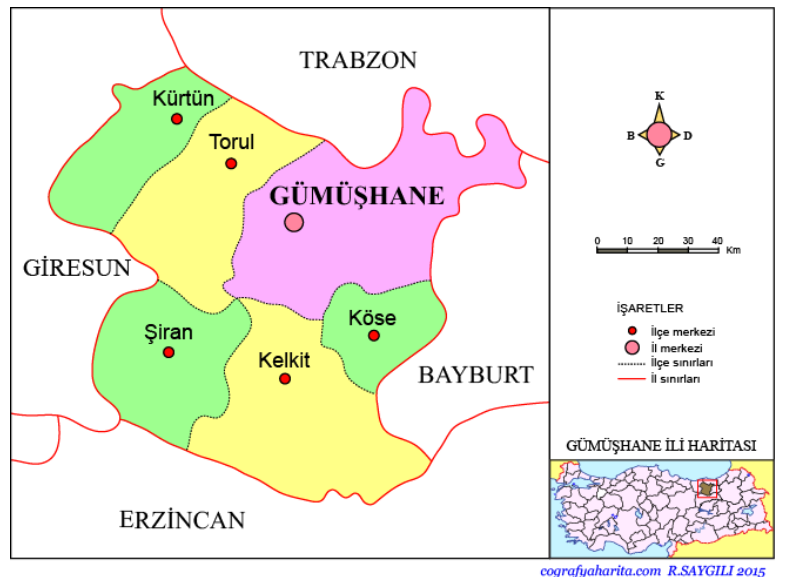

Şekil 1. Fasulye genotiplerinin toplandığı Gümüşhane ili haritası (Anonim 2019b).

Figure 1. Gümüşhane province map where bean genotypes were collected (Anonim 2019b) 


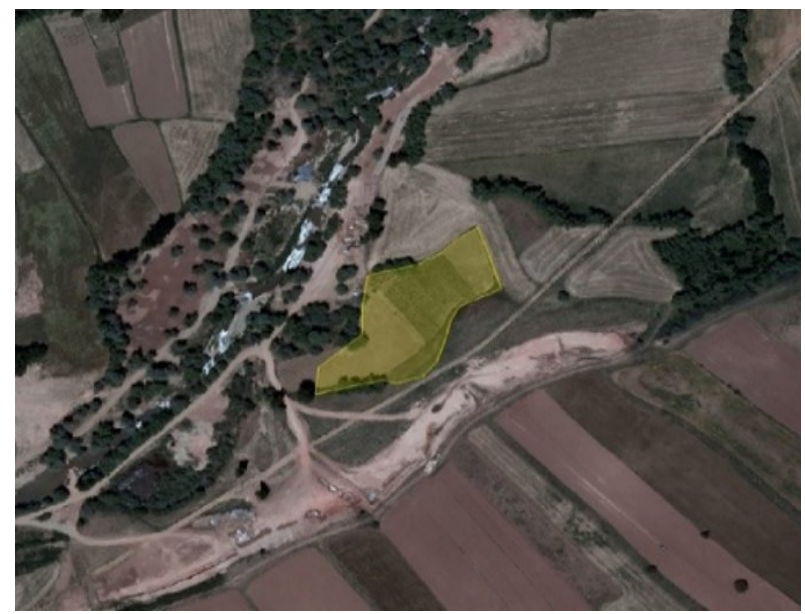

Şekil 2. Denemenin kurulduğu arazinin uydu görüntüsü (Anonim 2019c)

Figure 2. Satellite image of the land where the trial was established (Anonim 2019c).

\section{Araştırma yerinin iklim özellikleri}

Araştırmanın yürütüldüğü 2015 yılının vejetasyon periyodu, uzun yıllar ortalamasina kıyasla, daha yağışlı ve sıcak geçmiştir (Çizelge 3). Vejetasyon periyodunda düşen yağışın mevsim içerisindeki dağılımına bakıldığında, Haziran ayında kaydedilen yağışın uzun yıllar ortalamasından 15,2 $\mathrm{mm}$ daha düşük, Eylül ayında kaydedilen yağışın ise uzun yıllar ortalamasının iki katı civarında olduğu görülmektedir. Diğer taraftan, ürün y1lına ait en düşük ve en yüksek sıcaklık değerleri incelendiğinde, genel olarak vejetasyon periyodu boyunca fasulye gelișimini olumsuz etkileyebilecek uç sıcaklıkların meydana gelmediği anlaşılmaktadır.

\section{Tarla çalışmaları}

Genotipler, 2015 yılında Şansa Bağlı Tam Bloklar Deneme Deseninde 3 tekrarlamalı olarak Gümüşhane ili Kelkit ilçesi Öbektaş Beldesi'nde denemeye alınmıştır. Denemede kullanılan genotipler bloklarda bulunan sıralara şansa bağlı olarak dağıtılmış ve her blokta sıra arası $60 \mathrm{~cm}$ ve uzunluğu $5 \mathrm{~m}$ olan 49 bitki sırası yer almıştır. Ekim, 19 Mayıs 2015 tarihinde el ile 5-6 cm derinliğe yapılmıştır. Ekim sıklığı, sıra üzeri $25 \mathrm{~cm}$ ve sıra aras $60 \mathrm{~cm}$ olacak şekilde ayarlanmıştır. Deneme alanına, Tarımsal Değerleri Ölçme Denemeleri Teknik Talimatında belirtildiği üzere, ekimle birlikte dekara $4 \mathrm{~kg} \mathrm{~N}$ (\%21'lik amonyum sülfat) ve $6 \mathrm{~kg} \mathrm{P}_{2} \mathrm{O}_{5}$ (\%45'lik triple süper fosfat) uygulanmıştır (Anonim, 2001). Deneme alanı salma yöntemiyle toplamda 4 kere sulanmış; bunun bir tanesi çiçeklenme öncesinde, diğer üçü ise bakla bağlama ve tane olum döneminde uygulanmıştır. Parseller otlandıkça yabancı otlar çapa yapılarak kontrol altına alınmıştır. Deneme alanında herhangi bir hastalık belirtisi ve zararlıya rastlanmamış, bu nedenle hastalık ve zararlı mücadelesine ihtiyaç duyulmamıştır. Elle ayrı ayrı hasat edilen genotipler tarlada 4-5 gün kurutulduktan sonra ayrı ayrı harman edilmiştir.

Çizelge 2. Deneme alanı toprağının bazı fiziksel ve kimyasal özellikleri.

Table 2. Some physical and chemical properties of field soil.

\begin{tabular}{lcc} 
Temel özellikler & Analiz sonuçları & Anlamı \\
Basic characteristics & Analysis results & Meaning \\
\hline Bünye (Texture) & Tinlı (Loam) & Hafif alkali (Slightly alkaline) \\
pH & 7,86 & Çok az (Very little) \\
Organik madde (Organic matter) (\%) & 0,14 & \\
EC (mmhos/cm) & 0,36 & Az kireçli (Less chalky) \\
$\mathrm{Kireç} \mathrm{(Lime)} \mathrm{( \% )}$ & 4,09 & Tuzsuz (No salt) \\
Tuz (Salt) (\%) & 0,011 & Yeterli (Enough) \\
$\mathrm{P}_{2} \mathrm{O}$ ( $\left.\mathrm{kg} / \mathrm{da}\right)$ & 5,85 & Fazla (Much) \\
$\mathrm{K}_{2} \mathrm{O}(\mathrm{kg} / \mathrm{da})$ & 145,3 & \\
\hline
\end{tabular}

$\S$ Aydın ve Sezen (1995). 
V. SOYDAS, M. AYDIN, E. ELKOCA, E. İLHAN: GÜMÜȘHANE İLI YEREL FASULYE GENOTIPLERININ MORFOLOJIK VE TARIMSAL ÖZELLIKLER YÖNÜNDEN KARAKTERIZASYONU ÜZERINE BIR ÖN ÇALIŞMA

Çizelge 3. Gümüşhane ilinin ürün yılı (2015) ve uzun yıllar (1990-2014) ortalamasına ait bazı iklim verileri. §

Table 3. Some climate data of research year (2015) and long-term averages (1990-2014) in Gümüşhane province.

\begin{tabular}{|c|c|c|c|c|c|c|c|c|}
\hline \multirow{3}{*}{ Aylar (Months) } & \multirow{2}{*}{\multicolumn{2}{|c|}{$\begin{array}{l}\text { Toplam yağış }(\mathrm{mm}) \\
\text { Total rainfall }\end{array}$}} & \multicolumn{6}{|c|}{ Hava sıcaklığı (Air temperature) } \\
\hline & & & \multicolumn{2}{|c|}{$\begin{array}{l}\text { En düşük } \\
\text { Minimum }\end{array}$} & \multicolumn{2}{|c|}{$\begin{array}{l}\text { Ortalama } \\
\text { Average }\end{array}$} & \multicolumn{2}{|c|}{$\begin{array}{l}\text { En yüksek } \\
\text { Maximum }\end{array}$} \\
\hline & $\mathrm{UYO} \psi$ & 2015 & UYO & 2015 & UYO & 2015 & UYO & 2015 \\
\hline Mayıs (May) & 66,4 & 66,7 & 1,3 & 3,8 & 13,6 & 14,8 & 28,7 & 30,4 \\
\hline Haziran (June) & 46,2 & 31,0 & 8,9 & 6,3 & 17,2 & 18,0 & 32,2 & 32,0 \\
\hline Temmuz (July) & 15,2 & 19,3 & 8,6 & 10,5 & 20,3 & 22,0 & 36,0 & 36,9 \\
\hline Ağustos (August) & 15,7 & 12,4 & 9,3 & 11,2 & 20,6 & 23,2 & 36,1 & 38,2 \\
\hline Eylül (September) & 25,9 & 51,5 & 4,2 & 5,8 & 16,5 & 17,9 & 32,6 & 34,1 \\
\hline Toplam/ortalama & 169,4 & 180,9 & 6,5 & 7,5 & 17,6 & 19,2 & 33,1 & 34,3 \\
\hline
\end{tabular}

§ Gümüşhane Meteoroloji Müdürlügünün yıllık iklim rasatlarından alınmıştır. (Taken from the annual climate observations of the Gümüşhane Meteorology Directorate). $\psi$ Uzun yıllar ortalaması (Long-term average).

Çizelge 4. Fasulye genotiplerinde IPGRI ve EU-CPVO kriterlerine göre skala değerlerinin dağılımı.

Table 4. Distribution of scale values in bean genotypes according to IPGRI and EU-CPVO criteria.

\begin{tabular}{|c|c|c|c|}
\hline $\begin{array}{l}\text { Özellik } \\
\text { Character }\end{array}$ & $\begin{array}{l}\text { Siniflandirma } \\
\text { Classification }\end{array}$ & $\begin{array}{c}\text { Genotip sayis1 } \\
\text { Number of genotypes }\end{array}$ & $\begin{array}{l}\text { Yüzde }(\%) \\
\text { Percent }(\%)\end{array}$ \\
\hline \multicolumn{4}{|c|}{ Gövde (Stem) } \\
\hline Gövdede antosiyanin & 1 Yok (Absent) & 49 & 100 \\
\hline Anthocyanin in the stem & 9 Var (Present) & 0 & 0 \\
\hline & 3 Bodur (Bush) & 3 & 6,1 \\
\hline Büyüme şekli & 5 Yarı sarılıcı (Semi-climbing) & 41 & 83,7 \\
\hline & 7 Sar1lıcı (Climbing) & 5 & 10,2 \\
\hline \multicolumn{4}{|c|}{ Yaprak (Leaf) } \\
\hline \multirow{5}{*}{$\begin{array}{l}\text { Yaprak rengi } \\
\text { Leaf colour }\end{array}$} & 1 Çok açık yeşil (Very light green) & 0 & 0 \\
\hline & 3 Açık yeşil (Light green) & 4 & 8,2 \\
\hline & 5 Orta Yeşil (Medium green) & 45 & 91,8 \\
\hline & 7 Koyu yeşil (Dark green) & 0 & 0 \\
\hline & 9 Çok koyu yeşil (Very dark green) & 0 & 0 \\
\hline \multirow{3}{*}{$\begin{array}{l}\text { Yaprakta pürüzlülük } \\
\text { Leaf roughness }\end{array}$} & 3 Zayıf (Weak) & 18 & 36,7 \\
\hline & 5 Orta (Medium) & 22 & 44,9 \\
\hline & 7 Fazla (Much) & 9 & 18,4 \\
\hline Orta yaprakçık büyüklüğü & 3 Küçük (Small) & 1 & 2,1 \\
\hline \multirow{2}{*}{ Size of terminal leaflet } & 5 Orta (Medium) & 32 & 65,3 \\
\hline & 7 Büyük (Large) & 16 & 32,6 \\
\hline Orta yaprakçık şekli & 1 Üçgen (Triangle) & 48 & 97,9 \\
\hline \multirow{2}{*}{ Shape of terminal leaflet } & 3 Yuvarlak (Circular) & 1 & 2,1 \\
\hline & 5 Eşkenar dörtgen (Rhombus) & 0 & 0 \\
\hline \multirow{3}{*}{$\begin{array}{l}\text { Orta yaprakçık uç şekli } \\
\text { Shape of terminal leaflet tip }\end{array}$} & 3 Kisa (Short) & 2 & 4,1 \\
\hline & 5 Orta (Medium) & 8 & 16,3 \\
\hline & 7 Uzun (Tall) & 39 & 79,6 \\
\hline \multicolumn{4}{|c|}{ Çiçek (Flower) } \\
\hline \multirow{3}{*}{$\begin{array}{l}\text { Brakte boyutu } \\
\text { Bract size }\end{array}$} & 3 Küçük (Small) & 3 & 6,1 \\
\hline & 5 Orta (Medium) & 46 & 93,9 \\
\hline & 7 Büyük (Large) & 0 & 0 \\
\hline \multirow{4}{*}{$\begin{array}{l}\text { Brakte rengi } \\
\text { Bract color }\end{array}$} & 1 Yeşil (Green) & 49 & 100 \\
\hline & 2 Açık viyole (Light violet) & 0 & 0 \\
\hline & 3 Koyu mor (Dark purple) & 0 & 0 \\
\hline & 4 Diğger (Other) & 0 & 0 \\
\hline \multirow{3}{*}{$\begin{array}{l}\text { Brakte şekli } \\
\text { Bract shape }\end{array}$} & 1 Mizrak (Spear) & 44 & 89,8 \\
\hline & 3 Orta (Medium) & 5 & 10,2 \\
\hline & 5 Oval (Ovoid) & 0 & 0 \\
\hline \multirow{4}{*}{$\begin{array}{l}\text { Bayrak rengi } \\
\text { Standard color }\end{array}$} & 1 Beyaz (White) & 23 & 46,9 \\
\hline & 2 Pembe (Pink) & 9 & 18,4 \\
\hline & 3 Menekşe (Violet) & 17 & 34,7 \\
\hline & 4 Yeşil (Green) & 0 & 0 \\
\hline
\end{tabular}


Çizelge 4 (devam).

Table 4 (continued).

\begin{tabular}{|c|c|c|c|}
\hline $\begin{array}{l}\text { Özellik } \\
\text { Character }\end{array}$ & $\begin{array}{l}\text { Siniflandirma } \\
\text { Classification } \\
\end{array}$ & $\begin{array}{c}\text { Genotip say1s1 } \\
\text { Number of genotypes } \\
\end{array}$ & $\begin{array}{l}\text { Yüzde }(\%) \\
\text { Percent }(\%) \\
\end{array}$ \\
\hline $\begin{array}{l}\text { Kanatçık rengi } \\
\text { Wing color }\end{array}$ & $\begin{array}{l}1 \text { Beyaz (White) } \\
2 \text { Pembe (Pink) } \\
3 \text { Viyole (Violet) } \\
\end{array}$ & $\begin{array}{c}23 \\
26 \\
0\end{array}$ & $\begin{array}{c}46,9 \\
53,1 \\
0 \\
\end{array}$ \\
\hline $\begin{array}{l}\text { Kanatçıkların açılım durumu } \\
\text { Opening of wings }\end{array}$ & $\begin{array}{l}3 \text { Paralel (Parallel) } \\
5 \text { Ayrılmış (Separated) } \\
7 \text { İyice ayrılmış (Quite separated) }\end{array}$ & $\begin{array}{c}0 \\
49 \\
0\end{array}$ & $\begin{array}{c}0 \\
100 \\
0\end{array}$ \\
\hline $\begin{array}{l}\text { Çiçek boyutu/uzunluğu } \\
\text { Flower size/length }\end{array}$ & $\begin{array}{l}3 \text { Küçük (Small) }(10,0-13,9 \mathrm{~mm}) \\
5 \text { Orta (Medium) } 14,0-16,9 \mathrm{~mm}) \\
7 \text { Büyük (Large) }(17,0-20,0 \mathrm{~mm})\end{array}$ & $\begin{array}{l}12 \\
15 \\
22 \\
\end{array}$ & $\begin{array}{l}24,5 \\
30,6 \\
44,9 \\
\end{array}$ \\
\hline $\begin{array}{l}\text { Çiçek sap uzunluğu } \\
\text { Flower raceme length }\end{array}$ & $\begin{array}{l}3 \text { Kisa (Short) }(6,0-9,9 \mathrm{~mm}) \\
5 \text { Orta (Medium) }(10,0-13,9 \mathrm{~mm}) \\
7 \text { Uzun (Tall) }(14,0-17,0 \mathrm{~mm})\end{array}$ & $\begin{array}{c}11 \\
33 \\
5\end{array}$ & $\begin{array}{l}22,5 \\
67,3 \\
10,2\end{array}$ \\
\hline \multicolumn{4}{|c|}{ Bakla (Pod) } \\
\hline $\begin{array}{l}\text { Bakla rengi } \\
\text { Pod colour }\end{array}$ & $\begin{array}{l}\text { 1 Sarı (Yellow) } \\
2 \text { Yeşil (Green) } \\
3 \text { Viole (Violet) }\end{array}$ & $\begin{array}{c}0 \\
49 \\
0\end{array}$ & $\begin{array}{c}0 \\
100 \\
0\end{array}$ \\
\hline $\begin{array}{l}\text { Bakla renginin koyuluğu } \\
\text { Intensity of pod colour }\end{array}$ & $\begin{array}{l}3 \text { Hafif (Light) } \\
5 \text { Orta (Medium) } \\
7 \text { Koyu (Dark) }\end{array}$ & $\begin{array}{c}5 \\
44 \\
0 \\
\end{array}$ & $\begin{array}{c}10,2 \\
89,8 \\
0 \\
\end{array}$ \\
\hline $\begin{array}{l}\text { Baklada çift renk } \\
\text { Variegated color in pod }\end{array}$ & $\begin{array}{l}1 \text { Yok (Absent) } \\
9 \text { Var (Present) }\end{array}$ & $\begin{array}{c}49 \\
0\end{array}$ & $\begin{array}{c}100 \\
0\end{array}$ \\
\hline $\begin{array}{l}\text { Kilçılklılık } \\
\text { Stringy pod }\end{array}$ & $\begin{array}{l}1 \text { Yok (Absent) } \\
9 \text { Var (Present) }\end{array}$ & $\begin{array}{c}5 \\
44\end{array}$ & $\begin{array}{l}10,2 \\
89,8\end{array}$ \\
\hline $\begin{array}{l}\text { Bakla kesit şekli } \\
\text { Shape of pod section }\end{array}$ & $\begin{array}{l}\text { 1 Eliptik (Elliptical) } \\
2 \text { Kalp şekilde (Cordate) } \\
3 \text { Yuvarlak (Circular) } \\
4 \text { Sekiz Şeklinde (Shaped like eight) }\end{array}$ & $\begin{array}{c}49 \\
0 \\
0 \\
0\end{array}$ & $\begin{array}{c}100 \\
0 \\
0 \\
0\end{array}$ \\
\hline $\begin{array}{l}\text { Bakla genişliği } \\
\text { Pod width }\end{array}$ & $\begin{array}{l}3 \text { Dar (Narrow) } \\
5 \text { Orta (Medium) } \\
7 \text { Geniş (Broad) }\end{array}$ & $\begin{array}{c}4 \\
45 \\
0\end{array}$ & $\begin{array}{c}8,2 \\
91,8 \\
0\end{array}$ \\
\hline $\begin{array}{l}\text { Baklada kıvrım } \\
\text { Curvature of pod }\end{array}$ & $\begin{array}{l}1 \text { Düz (Straight) } \\
3 \text { Hafif (Mild) } \\
5 \text { Orta (Medium) } \\
7 \text { Kuvveti (Strong) } \\
9 \text { Çok Kuvvetli (Very strong) }\end{array}$ & $\begin{array}{c}10 \\
28 \\
11 \\
0 \\
0\end{array}$ & $\begin{array}{c}20,4 \\
57,1 \\
22,5 \\
0 \\
0\end{array}$ \\
\hline $\begin{array}{l}\text { Bakla kıvrımının şekli } \\
\text { Shape of pod curvature }\end{array}$ & $\begin{array}{l}1 \text { İçbükey (Concave) } \\
2 \text { S şekli (S shaped) } \\
3 \text { Dişbükey (Convex) }\end{array}$ & $\begin{array}{c}39 \\
0 \\
0\end{array}$ & $\begin{array}{c}100 \\
0 \\
0\end{array}$ \\
\hline $\begin{array}{l}\text { Gaganın kıvrılması } \\
\text { Curvature of beak }\end{array}$ & $\begin{array}{l}1 \text { Çok güçsüz (Very weak) } \\
3 \text { Güçsüz (Weak) } \\
5 \text { Orta (Medium) } \\
7 \text { Güçlü (Strong) } \\
9 \text { Çok güçlü (Very strong) }\end{array}$ & $\begin{array}{c}44 \\
0 \\
5 \\
0 \\
0 \\
\end{array}$ & $\begin{array}{c}89,8 \\
0 \\
10,2 \\
0 \\
0 \\
\end{array}$ \\
\hline $\begin{array}{l}\text { Gaganın oluşum şekli } \\
\text { Beak formation }\end{array}$ & $\begin{array}{l}1 \text { Güçlü (Strong) } \\
2 \text { Orta (Medium) } \\
3 \text { Güçsüz (Weak) }\end{array}$ & $\begin{array}{c}0 \\
49 \\
0\end{array}$ & $\begin{array}{c}0 \\
100 \\
0\end{array}$ \\
\hline $\begin{array}{l}\text { Gaganın uzunluğu } \\
\text { Beak length }\end{array}$ & $\begin{array}{l}3 \text { Kisa (Short) } \\
5 \text { Orta (Medium) } \\
7 \text { Uzun (Tall) }\end{array}$ & $\begin{array}{c}0 \\
5 \\
44\end{array}$ & $\begin{array}{c}0 \\
10,2 \\
89,8\end{array}$ \\
\hline \multicolumn{4}{|c|}{ Tohum (Seed) } \\
\hline $\begin{array}{l}\text { Tohum şekli } \\
\text { Seed shape }\end{array}$ & $\begin{array}{l}1 \text { Dairesel (Circular) } \\
2 \text { Dairesel-eliptik (Circular-elliptical) } \\
3 \text { Eliptik (Elliptical) } \\
4 \text { Böbrek (Kidney) }\end{array}$ & $\begin{array}{c}28 \\
21 \\
0 \\
0\end{array}$ & $\begin{array}{c}57,1 \\
42,9 \\
0 \\
0\end{array}$ \\
\hline
\end{tabular}


V. SOYDAS, M. AYDIN, E. ELKOCA, E. İLHAN: GÜMÜSHANE İLI YEREL FASULYE GENOTIPLERININ MORFOLOJIK VE TARIMSAL ÖZELLIKLER YÖNÜNDEN KARAKTERIZASYONU ÜZERINE BIR ÖN ÇALIŞMA

Çizelge 4 (devam)

Table 4 (continued).

\begin{tabular}{|c|c|c|c|}
\hline $\begin{array}{l}\text { Özellik } \\
\text { Character } \\
\end{array}$ & $\begin{array}{l}\text { Siniflandirma } \\
\text { Classification } \\
\end{array}$ & $\begin{array}{c}\text { Genotip say1s1 } \\
\text { Number of genotypes }\end{array}$ & $\begin{array}{l}\text { Yüzde (\%) } \\
\text { Percent (\%) }\end{array}$ \\
\hline $\begin{array}{l}\text { Tohum renginin say1s1 } \\
\text { Number of seed color }\end{array}$ & $\begin{array}{l}1 \text { Bir (One) } \\
2 \text { İki (Two) } \\
3 \text { İkiden fazla (More than two) }\end{array}$ & $\begin{array}{c}49 \\
0 \\
0\end{array}$ & $\begin{array}{c}100 \\
0 \\
0\end{array}$ \\
\hline $\begin{array}{l}\text { Tohumun ana rengi } \\
\text { Seed main color }\end{array}$ & $\begin{array}{l}1 \text { Beyaz (White) } \\
2 \text { Yeşil (Green) } \\
3 \text { Gri (Grey) } \\
4 \text { Sarı (Yellow) } \\
5 \text { Koyu sarı (Dark yellow) } \\
6 \text { Kahverengi (Brown) } \\
7 \text { Kirmızı (Red) } \\
8 \text { Viyole (Violet) } \\
9 \text { Siyah (Black) }\end{array}$ & $\begin{array}{c}49 \\
0 \\
0 \\
0 \\
0 \\
0 \\
0 \\
0 \\
0\end{array}$ & $\begin{array}{c}100 \\
0 \\
0 \\
0 \\
0 \\
0 \\
0 \\
0 \\
0\end{array}$ \\
\hline $\begin{array}{l}\text { Hilum halkasının rengi } \\
\text { Color of hilum ring }\end{array}$ & $\begin{array}{l}1 \text { Tohum rengi ile aynı (Same as seed } \\
\text { colour) } \\
2 \text { Tohum renginden farklı (Not same as } \\
\text { seed colour) }\end{array}$ & $\begin{array}{c}48 \\
1\end{array}$ & $\begin{array}{l}97,9 \\
2,1\end{array}$ \\
\hline
\end{tabular}

Ülkemizin farklı bölgelerinden toplanan fasulye genotiplerinin karakterizasyonu üzerine yapılan diğer çalışmalarda da büyüme şekli bakımından genotipler arasında farkların olduğu ortaya koyulmuştur. Orta Karadeniz Bölgesinden topladığ 292 adet fasulye genotipinin tanımlamasını yapan Sözen (2006), genotiplerden 88 tanesinin bodur $(\% 30,1), 29$ tanesinin yarı sarılıcı $(\% 9,9)$ ve 175 tanesinin ise $(\% 60,0)$ sarılıc formda olduğunu saptamıștır. Kuzey Doğu Anadolu Bölgesi ve Çoruh Vadisi'nden topladıkları 418 adet fasulye genotipi ile çalışan Kantar ve ark. (2010) ise genotiplerden \%7,4'ünün (31 adet) bodur, $\% 20,8$ 'inin (87 adet) yarı sar1lıc1 ve \%71,8'inin ise (300 adet) sarılıcı özellikte olduğunu belirlemişlerdir.

\section{Yaprak özellikleri}

Karakterizasyonu yapılan genotiplerin 4 tanesinde yaprak renginin açık yeşil (kayıt no 1, 3, 6, 16), diğerlerinde ise orta yeşil olduğu tespit edilmiștir. Genotiplerden 18 'inde $(\% 36,7)$ yaprakların zayıf, 22 'sinde $(\% 44,9)$ orta ve 9'unda $(\% 18,4)$ ise fazla pürüzlü olduğu saptanmıştır. Orta yaprakçığın 1 genotipte (kayıt no 23) küçük, 32 genotipte orta ve 16 genotipte büyük; şeklinin ise 48 genotipte üçgen ve 1 genotipte (kayıt no 33) yuvarlak olduğu belirlenmiştir. Orta yaprakçık ucunun 2 genotipte (kayıt no 24, 30) kısa, 8 genotipte (kayıt no 5, 9, $22,28,35,39,42,44)$ orta, 39 genotipte ise uzun olduğu gözlenmiştir (Çizelge 4). Yaprak özellikleri genetik faktörlerin etkisi altında șekillenmekte (Hofer ve ark., 2001; Kessler ve Sinha, 2004) ve bu durum genotipler arasında yaprak özellikleri bakımından önemli varyasyonların görülmesine neden olmaktadır. Nitekim araştırmamızda olduğu gibi, fasulyede yapılan diğer karakterizasyon çalışmalarında da yaprak özellikleri bakımından genotipler arasında çeşitliliğin bulunduğu rapor edilmiştir (Kantar ve ark., 2010; Erdinç ve ark., 2013; Yeken ve ark., 2019; B1y1klı ve ark., 2021).

\section{Çiçek özellikleri}

Brakte renginin tüm genotiplerde yeşil; boyutunun 3 genotipte küçük (kayıt no 33, 41, 44), diğerlerinde ise büyük olduğu belirlenmiştir. Genotipler brakte şekli bakımından incelendiğinde 5 tanesinin orta (kayit no 8, 9, 24, 40, 44), 44 tanesinin ise mızrak biçiminde olduğu görülmüştür (Çizelge 4). Bayrak yaprak rengi bakımından genotipler arasında varyasyon gözlenmiş ve 17 genotipte menekșe $(\% 34,7), 23$ genotipte beyaz $(\% 46,9)$ ve diğer 9 genotipte ise $(\% 18,4)$ pembe renkli olduğu belirlenmiştir (Çizelge 4). Kanatçık özellikleri bakımından genotipler incelendiğinde ise 23 genotipin $(\% 46,9)$ beyaz, 26 genotipin $(\% 53,1)$ pembe renkli kanatçığa sahip olduğu ve tüm genotiplerde kanatçıkların birbirinden ayrık durduğu saptanmıştır (Çizelge 4). Her genotip sırasından rastgele alınan 10 çiçekte yapılan ölçümlerde, çiçek uzunluğunun genotiplerin \%24,5'inde 10-13,9 mm, \%30,6'sinda 14-16,9 
$\mathrm{mm}$ ve \%44,9'unda ise $17-20 \mathrm{~mm}$ arasinda yer aldığ belirlenmiştir. Benzer şekilde genotiplerin sap uzunlukları da 6-17 mm arasında olmak üzere geniş bir aralıkta değişim göstermiş ve sap uzunluğunun 11 genotipte k1sa $(6-9,9 \mathrm{~mm}), 33$ genotipte orta $(10-13,9 \mathrm{~mm})$ ve 5 genotipte ise uzun (14-17 mm) olduğu belirlenmiştir (Çizelge 4). Bütün bu gözlem ve ölçümlerden elde edilen veriler, incelenen genotiplerin çiçek özellikleri bakımından geniş bir varyasyona sahip olduğunu ifade etmektedir. Bu çiçek özellikleri bakımından genotipler arasında farklılıkların bulunduğu diğer birçok araştırma sonucunda da ortaya koyulmuştur (Kantar ve ark., 2010; Erdinç ve ark., 2013; Ekincialp ve Şensoy, 2013; Yeken ve ark., 2019).

\section{Bakla özellikleri}

Tüm genotiplerde bakla renginin yeşil; koyuluğunun ise 5 genotipte hafif (kayıt no 30, 35, $44,46,47)$, geri kalan 44 genotipte ise orta olduğu tespit edilmiştir. Baklalar kılçıklılık bakımından incelendiğinde 5 genotipin kılçıksız (kayıı no 2, $13,32,33,38)$, diğer 44 genotipin $(\% 89,8)$ ise kılçıklı olduğu anlaşılmıştır (Çizelge 4). Baklanın kılçıklı olması fasulyenin taze olarak tüketilmesini olumsuz yönde etkilemekte ve bu nedenle taze fasulye islahında kılçıksız genotipler büyük önem taşımaktadır. Dolayısıyla araştırmamızda kılçıksız olduğu tespit edilen genotipler ileride yapılacak taze fasulye çeşit geliştirme çalışmalarında materyal olarak kullanılabilecektir. Bakla kesit şekli tüm genotiplerde eliptik olup bakla genişliği 4 genotipte dar (kayıt no 2, 22, 38, 40), 45 genotipte ise ortadır. Bakla 10 genotipte düz $(\% 20,4) ; 28$ genotipte hafif kivrık $(\% 57,1)$ ve 11 genotipte ise $(\% 22,5)$ orta seviyede k1vrıktır. Gaga kıvrılması 44 genotipte çok güçsüz, 5 genotipte orta (kayıt no 16, 17, 23, 24, 39); gaganın oluşum şekli tüm genotiplerde orta; gaganın uzunluğu 5 genotipte orta (kayit no 17, 18, 24, 45, 49), 44 genotipte uzundur (Çizelge 4). Araştırmamızda olduğu gibi, Batı Anadolu Bölgesi (Yeken ve ark., 2019), Kuzey Doğu Anadolu Bölgesi ve Çoruh vadisi (Kantar ve ark., 2010) ile Doğu Karadeniz Bölgesi (Sözen ve ark., 2014) fasulye genetik kaynaklarının karakterizasyonuna yönelik olarak ülkemizde yürütülen diğer çalışmalarda da bakla özellikleri bakımından genotipler arasında önemli varyasyonların bulunduğu rapor edilmiştir.

\section{Tohum özellikleri}

Genotiplerin tamamında tane beyaz renkli ve şeker tipinde olup, tane şekli 21 genotipte dairesel-eliptik $(\% 42,9), 28$ genotipte $(\% 57,1)$ ise daireseldir (Çizelge 4). Hilum halkasının rengi 48 genotipte tane rengi ile aynı olup, yalnızca bir genotipte (kayıt no 30) koyu sarı olduğu gözlemlenmiştir. Ülkemizde, şeker tane tipi piyasada oldukça rağbet görmekte ve şeker tane tipine sahip tescilli çeşitlere ihtiyaç duyulmaktadır. $\mathrm{Bu}$ araştırmada karakterizasyonu yapılan bütün genotiplerin şeker tane tipine sahip olması, bu koleksiyonun şeker tane tipinde çeşit geliştirme çalışmalarına büyük katkı sağlayacağı beklenmektedir.

\section{Genotiplerin tarımsal özellikleri}

Çalışmada incelenen fasulye genotiplerinin bazı tarımsal özelliklerine ait veriler Çizelge $5^{\text {' de }}$ ayrıntılı olarak verilmiştir. 
Çizelge 5. Fasulye genotiplerinin bazı tarımsal özellikleri.

Table 5. Some agronomical properties of bean genotypes.

\begin{tabular}{|c|c|c|c|c|c|c|c|c|c|}
\hline $\begin{array}{l}\text { Genotip no } \\
\text { Genotype } \\
\text { no }\end{array}$ & $\begin{array}{l}\text { ÇS \& } \\
\text { (gün) } \\
\text { (day) }\end{array}$ & $\begin{array}{l}\text { ÇÇS } \\
\text { (gün) } \\
\text { (day) }\end{array}$ & $\begin{array}{c}\text { OS } \\
\text { (gün) } \\
\text { (day) }\end{array}$ & $\begin{array}{l}\text { BB } \\
(\mathrm{cm})\end{array}$ & İBY $(\mathrm{cm})$ & $\begin{array}{c}\text { BBS } \\
\text { (adet) } \\
\text { (nu.) }\end{array}$ & $\begin{array}{l}\text { BTS } \\
\text { (adet) } \\
\text { (nu.) }\end{array}$ & YTA (g) & $\begin{array}{c}\text { TV } \\
\left(\mathrm{g} / \mathrm{m}^{2}\right)\end{array}$ \\
\hline 1 & $13,0 \mathrm{~b}$ & $54,0 \mathrm{~d}$ & $125,0 \mathrm{o}-\mathrm{q}$ & $121,3 \mathrm{i}$ & 13,1 op & $22,1 \mathrm{e}$ & $5,0 \mathrm{e}-1$ & $61,4 \mathrm{o}$ & $346,7 \mathrm{e}$ \\
\hline 2 & $13,0 \mathrm{~b}$ & $54,0 \mathrm{~d}$ & $124,0 \mathrm{p}-\mathrm{s}$ & $78,4 \mathrm{w}$ & $10,2 \mathrm{qr}$ & 14,9 i-1 & $5,2 \mathrm{~d}-\mathrm{k}$ & $93,4 \mathrm{f}$ & 359,1 çd \\
\hline 3 & $13,0 \mathrm{~b}$ & $54,0 \mathrm{~d}$ & $123,0 \mathrm{q}-\mathrm{t}$ & $120,3 \mathrm{ij}$ & $18,0 \mathrm{hi}$ & 12,4 op & 4,4 i-p & $67,5 \mathrm{~m}$ & $174,8 \mathrm{u}$ \\
\hline 4 & $11,0 \mathrm{c}$ & $54,0 \mathrm{~d}$ & $126,7 \mathrm{~m}-\mathrm{o}$ & $125,0 \mathrm{~h}$ & $20,1 \mathrm{fg}$ & $19,8 \mathrm{fg}$ & $6,9 \mathrm{a}$ & 55,4 p-r & $424,0 \mathrm{a}$ \\
\hline 5 & $11,0 \mathrm{c}$ & $57,0 \mathrm{c}$ & 130,0 h-k & 98,3 ş & $21,8 \mathrm{de}$ & $17,1 \mathrm{~h}$ & $3,4 \mathrm{q}-\mathrm{s}$ & 104,5 ç & $286,2 \mathrm{~lm}$ \\
\hline 6 & $11,0 \mathrm{c}$ & $62,0 \mathrm{a}$ & $134,0 \mathrm{~d}-\mathrm{f}$ & $106,9 \mathrm{q}$ & $9,9 \mathrm{qr}$ & $19,7 \mathrm{fg}$ & $4,8 \mathrm{~g}-1$ & $55,3 \mathrm{p}-\mathrm{r}$ & 293,4 j-1 \\
\hline 7 & $13,0 \mathrm{~b}$ & $62,0 \mathrm{a}$ & $133,0 \mathrm{e}-\mathrm{g}$ & $114,9 \mathrm{~m}$ & $20,1 \mathrm{fg}$ & $10,2 \mathrm{~s}$ & $7,4 \mathrm{a}$ & $53,6 \mathrm{r}$ & $204,9 \mathrm{r}$ \\
\hline 8 & $11,0 \mathrm{c}$ & $57,0 \mathrm{c}$ & 125,7 op & $133,6 \mathrm{f}$ & $22,6 \mathrm{~cd}$ & $12,1 \mathrm{o}-\mathrm{q}$ & $5,1 \mathrm{e}-1$ & $125,4 \mathrm{a}$ & $325,3 \mathrm{f}$ \\
\hline 9 & $11,0 \mathrm{c}$ & $60,0 \mathrm{~b}$ & $130,3 \mathrm{~h}-\mathrm{j}$ & $86,2 \mathrm{u}$ & 13,0 op & $27,7 \mathrm{c}$ & $4,8 \mathrm{~g}-1$ & $32,3 \mathrm{v}$ & $228,0 \mathrm{q}$ \\
\hline 10 & $14,0 \mathrm{~b}$ & $60,0 \mathrm{~b}$ & $132,0 \mathrm{f}-\mathrm{h}$ & $102,1 \mathrm{~s}$ & $13,9 \mathrm{~m}-\mathrm{o}$ & $24,3 \mathrm{~d}$ & $5,2 \mathrm{~d}-\mathrm{k}$ & $38,6 \mathrm{ü}$ & 246,5 оӧ \\
\hline 11 & $13,0 \mathrm{~b}$ & $60,0 \mathrm{~b}$ & $128,7 \mathrm{j}-\mathrm{m}$ & $140,6 \mathrm{~d}$ & $17,7 \mathrm{i}$ & 15,1 i-1 & 4,7 g-n & $64,2 n$ & 257,2 o \\
\hline 12 & $13,0 \mathrm{~b}$ & $54,0 \mathrm{~d}$ & $122,0 \mathrm{st}$ & $93,3 \mathrm{t}$ & 12,9 op & $20,2 \mathrm{f}$ & $5,2 \mathrm{~d}-\mathrm{k}$ & 70,91 & $375,0 \mathrm{c}$ \\
\hline 13 & $14,0 \mathrm{~b}$ & $62,0 \mathrm{a}$ & $135,0 \mathrm{c}-\mathrm{e}$ & 156,7 a & $15,8 \mathrm{j}-1$ & $19,8 \mathrm{fg}$ & $4,8 \mathrm{~g}-1$ & $50,5 \mathrm{~s}$ & $266,9 \mathrm{n}$ \\
\hline 14 & $16,0 \mathrm{a}$ & $62,0 \mathrm{a}$ & $135,0 \mathrm{c}-\mathrm{e}$ & 146,8 ç & 13,1 op & $32,7 \mathrm{~b}$ & $5,8 \mathrm{c}-\mathrm{f}$ & $27,6 \mathrm{w}$ & $290,5 \mathrm{kl}$ \\
\hline 15 & $16,0 \mathrm{a}$ & $62,0 \mathrm{a}$ & $137,0 \mathrm{bc}$ & $83,1 \mathrm{v}$ & $22,9 \mathrm{~cd}$ & $11,7 \mathrm{qr}$ & $3,7 \mathrm{o}-\mathrm{s}$ & $127,0 \mathrm{a}$ & $356,1 \mathrm{~d}$ \\
\hline 16 & $14,0 \mathrm{~b}$ & $54,0 \mathrm{~d}$ & 123,3 q-s & $136,9 \mathrm{e}$ & $9,1 \mathrm{r}$ & $17,2 \hat{h}$ & $4,6 \mathrm{~g}-\mathrm{o}$ & $51,3 \mathrm{~s}$ & $233,8 \mathrm{pq}$ \\
\hline 17 & $14,0 \mathrm{~b}$ & $60,0 \mathrm{~b}$ & 133,0 e-g & $114,9 \mathrm{~m}$ & $13,9 \mathrm{~m}-\mathrm{o}$ & $49,6 \mathrm{a}$ & $4,2 \mathrm{k}-\mathrm{r}$ & $27,4 \mathrm{w}$ & $281,8 \mathrm{~m}$ \\
\hline 18 & $13,0 \mathrm{~b}$ & $60,0 \mathrm{~b}$ & $131,0 \mathrm{~g}-\mathrm{i}$ & $42,6 \mathrm{z}$ & $10,3 \mathrm{qr}$ & $28,2 \mathrm{c}$ & $3,1 \mathrm{~s}$ & $65,5 \mathrm{mn}$ & 295,2 jk \\
\hline 19 & $14,0 \mathrm{~b}$ & $60,0 \mathrm{~b}$ & $128,0 \mathrm{k}-\mathrm{n}$ & $114,3 \mathrm{mn}$ & $15,7 \mathrm{kl}$ & $10,3 \mathrm{~s}$ & $3,3 \mathrm{q}-\mathrm{s}$ & $106,9 \mathrm{c}$ & $233,4 \mathrm{pq}$ \\
\hline 20 & $13,0 \mathrm{~b}$ & $60,0 \mathrm{~b}$ & 133,0 e-g & $148,8 \mathrm{c}$ & 16,7 i-k & $22,4 \mathrm{e}$ & $5,4 \mathrm{c}-\mathrm{i}$ & $23,4 \mathrm{y}$ & $120,4 \mathrm{w}$ \\
\hline 21 & $11,0 \mathrm{c}$ & $60,0 \mathrm{~b}$ & $125,0 \mathrm{o}-\mathrm{q}$ & $150,7 \mathrm{~b}$ & $27,0 \mathrm{a}$ & $17,2 \mathrm{~h}$ & $6,3 \mathrm{bc}$ & 57,4 öp & $314,8 \mathrm{gg}$ \\
\hline 22 & $14,0 \mathrm{~b}$ & $60,0 \mathrm{~b}$ & 130,0 h-k & $123,8 \mathrm{~h}$ & $22,9 \mathrm{~cd}$ & $14,4 \mathrm{k}-\mathrm{m}$ & $5,9 \mathrm{~b}-\mathrm{e}$ & $42,5 \mathrm{tu}$ & 190,8 şt \\
\hline 23 & $14,0 \mathrm{~b}$ & $54,0 \mathrm{~d}$ & $121,0 \mathrm{t}$ & 109,6 op & $6,7 \mathrm{~s}$ & $20,3 \mathrm{f}$ & $3,3 \mathrm{q}-\mathrm{s}$ & 59,1 ö & 190,5 şt \\
\hline 24 & $13,0 \mathrm{~b}$ & $54,0 \mathrm{~d}$ & 124,0 p-s & $119,7 \mathrm{j}$ & $9,3 \mathrm{r}$ & $17,6 \mathrm{~h}$ & $4,7 \mathrm{~g}-\mathrm{n}$ & $78,6 \mathrm{ij}$ & 305,4 hi \\
\hline 25 & $16,0 \mathrm{a}$ & $60,0 \mathrm{~b}$ & 130,0 h-k & $124,4 \mathrm{~h}$ & $19,7 \mathrm{fg}$ & $14,7 \mathrm{j}-1$ & $5,3 \mathrm{c}-\mathrm{j}$ & $76,6 \mathrm{jk}$ & 309,5 ğh \\
\hline 26 & $16,0 \mathrm{a}$ & $60,0 \mathrm{~b}$ & 127,0 l-o & $113,1 \mathrm{n}$ & $13,9 \mathrm{~m}-\mathrm{o}$ & $12,3 \mathrm{o}-\mathrm{q}$ & $4,11-r$ & $86,2 \breve{g}$ & $226,4 \mathrm{q}$ \\
\hline 27 & $16,0 \mathrm{a}$ & $60,0 \mathrm{~b}$ & 130,0 h-k & 98,3 ş & 12,9 op & $10,4 \mathrm{~s}$ & $4,9 \mathrm{~g}-1$ & 103,6 ç & 251,0 op \\
\hline 28 & $14,0 \mathrm{~b}$ & $57,0 \mathrm{c}$ & 125,7 op & $130,0 \mathrm{~g}$ & 13,3 o & 12,4 op & $4,9 \mathrm{~g}-1$ & $95,7 \mathrm{de}$ & $313,1 \mathrm{~g}-\mathrm{h}$ \\
\hline 29 & $13,0 \mathrm{~b}$ & $60,0 \mathrm{~b}$ & $130,0 \mathrm{~h}-\mathrm{k}$ & $52,6 \mathrm{y}$ & $15,0 \mathrm{~lm}$ & $9,2 \mathrm{t}$ & $5,2 \mathrm{~d}-\mathrm{k}$ & 117,8 b & $286,6 \mathrm{~lm}$ \\
\hline 30 & $14,0 \mathrm{~b}$ & $60,0 \mathrm{~b}$ & 130,7 h-j & $119,8 \mathrm{j}$ & 12,9 op & 15,3 i-k & $3,8 \mathrm{~m}-\mathrm{s}$ & $76,9 \mathrm{j}$ & 246,5 оӧ \\
\hline 31 & $16,0 \mathrm{a}$ & $57,0 \mathrm{c}$ & $125,0 \mathrm{o}-\mathrm{q}$ & $149,8 \mathrm{bc}$ & 14,8 1-n & $14,2 \mathrm{~lm}$ & $5,2 \mathrm{~d}-\mathrm{k}$ & $54,6 \mathrm{qr}$ & 203,2 rs \\
\hline 32 & $17,0 \mathrm{a}$ & $57,0 \mathrm{c}$ & $127,01-0$ & 137,9 e & $22,9 \mathrm{~cd}$ & $17,4 \mathrm{~h}$ & $3,8 \mathrm{~m}-\mathrm{s}$ & 55,6 p-r & 202,1 rs \\
\hline 33 & $13,0 \mathrm{~b}$ & $54,0 \mathrm{~d}$ & $122,3 \mathrm{r}-\mathrm{t}$ & $124,9 \mathrm{~h}$ & $17,1 \mathrm{ij}$ & $19,7 \mathrm{fg}$ & $5,4 \mathrm{c}-\mathrm{h}$ & $56,3 \mathrm{pq}$ & 299,2 ij \\
\hline 34 & $14,0 \mathrm{~b}$ & $54,0 \mathrm{~d}$ & 124,3 p-r & $61,3 \times$ & $10,6 \mathrm{q}$ & $11,3 \mathrm{qr}$ & $3,8 \mathrm{~m}-\mathrm{s}$ & $96,5 \mathrm{~d}$ & $233,8 \mathrm{pq}$ \\
\hline 35 & $13,0 \mathrm{~b}$ & $54,0 \mathrm{~d}$ & $124,0 \mathrm{p}-\mathrm{s}$ & $130,7 \mathrm{~g}$ & 12,9 op & $13,7 \mathrm{~m}$ & $6,1 \mathrm{~b}-\mathrm{d}$ & $81,5 \mathrm{~h}$ & 365,2 ç \\
\hline 36 & $14,0 \mathrm{~b}$ & $57,0 \mathrm{c}$ & $126,0 \mathrm{n}-\mathrm{p}$ & $119,3 \mathrm{j}$ & $24,9 \mathrm{~b}$ & $10,3 \mathrm{~s}$ & $4,7 \mathrm{~g}-\mathrm{n}$ & $90,8 \mathrm{~g}$ & 243,7 оӧ \\
\hline 37 & $16,0 \mathrm{a}$ & $60,0 \mathrm{~b}$ & 129,7 i-k & $109,5 \mathrm{p}$ & 14,9 l-n & $15,4 \mathrm{ij}$ & $4,3 \mathrm{j}-\mathrm{q}$ & $74,5 \mathrm{k}$ & 238,7 öp \\
\hline 38 & $16,0 \mathrm{a}$ & $57,0 \mathrm{c}$ & 127,0 l-o & $139,6 \mathrm{~d}$ & 23,7 bn & $17,4 \mathrm{~h}$ & $4,3 \mathrm{j}-\mathrm{q}$ & $43,8 \mathrm{t}$ & $161,0 \ddot{u}$ \\
\hline 39 & $13,0 \mathrm{~b}$ & $54,0 \mathrm{~d}$ & $118,3 \mathrm{u}$ & 110,9 o & $13,9 \mathrm{~m}-\mathrm{o}$ & $11,4 \mathrm{qr}$ & $4,6 \mathrm{~g}-\mathrm{o}$ & 94,3 ef & $280,5 \mathrm{~m}$ \\
\hline 40 & $14,0 \mathrm{~b}$ & $60,0 \mathrm{~b}$ & $137,0 \mathrm{bc}$ & $116,3 \mathrm{kl}$ & 20,8 ef & $19,3 \mathrm{~g}$ & $5,6 \mathrm{c}-\mathrm{g}$ & $64,7 \mathrm{n}$ & $395,1 \mathrm{~b}$ \\
\hline 41 & $16,0 \mathrm{a}$ & $62,0 \mathrm{a}$ & $136,0 \mathrm{~cd}$ & $119,9 \mathrm{j}$ & 12,8 op & $14,3 \mathrm{~lm}$ & $3,1 \mathrm{~s}$ & $80,8 \mathrm{hi}$ & $183,4 \mathrm{t}$ \\
\hline 42 & $14,0 \mathrm{~b}$ & $57,0 \mathrm{c}$ & $125,0 \mathrm{o}-\mathrm{q}$ & 109,8 op & 13,7 no & $17,6 \mathrm{~h}$ & $4,9 \mathrm{~g}-1$ & $41,5 \mathrm{u}$ & 195,2 sş \\
\hline 43 & $13,0 \mathrm{~b}$ & $57,0 \mathrm{c}$ & 129,0 i-1 & $115,1 \mathrm{~lm}$ & 14,8 1-n & $11,1 \mathrm{rs}$ & $5,2 \mathrm{~d}-\mathrm{k}$ & $106,9 \mathrm{c}$ & $320,1 \mathrm{fg}$ \\
\hline 44 & $14,0 \mathrm{~b}$ & $57,0 \mathrm{c}$ & $126,0 \mathrm{n}-\mathrm{p}$ & $104,7 \mathrm{r}$ & $13,9 \mathrm{~m}-\mathrm{o}$ & $15,6 \mathrm{ij}$ & $4,9 \mathrm{~g}-1$ & 24,3 xy & $83,7 \mathrm{z}$ \\
\hline 45 & $16,0 \mathrm{a}$ & $60,0 \mathrm{~b}$ & $139,0 \mathrm{ab}$ & $129,9 \mathrm{~g}$ & 13,1 op & 12,7 no & $4,8 \mathrm{~g}-1$ & $46,2 \mathrm{~s}$ & $162,1 \ddot{u}$ \\
\hline 46 & $16,0 \mathrm{a}$ & $60,0 \mathrm{~b}$ & 130,0 h-k & $103,0 \mathrm{~s}$ & $19,2 \mathrm{gh}$ & $13,5 \mathrm{mn}$ & $5,2 \mathrm{~d}-\mathrm{k}$ & $31,1 \mathrm{v}$ & $104,5 \times$ \\
\hline 47 & $14,0 \mathrm{~b}$ & $60,0 \mathrm{~b}$ & $128,0 \mathrm{k}-\mathrm{n}$ & $116,8 \mathrm{k}$ & 12,8 op & $14,2 \mathrm{~lm}$ & $5,3 \mathrm{c}-\mathrm{i}$ & 25,9 wx & $92,9 y$ \\
\hline 48 & $13,0 \mathrm{~b}$ & $60,0 \mathrm{~b}$ & 129,0 i-1 & $149,7 \mathrm{bc}$ & $11,9 \mathrm{p}$ & $15,8 \mathrm{i}$ & $4,8 \mathrm{~g}-1$ & $33,1 \mathrm{v}$ & $141,6 \mathrm{v}$ \\
\hline 49 & $16,0 \mathrm{a}$ & $62,0 \mathrm{a}$ & $141,0 \mathrm{a}$ & 110,0 op & $15,6 \mathrm{kl}$ & $14,4 \mathrm{k}-\mathrm{m}$ & $4,8 \mathrm{~g}-1$ & 24,2 xy & 90,4 yz \\
\hline $\begin{array}{l}\text { Ortalama } \\
\text { Average }\end{array}$ & 13,9 & 58,2 & 128,7 & 115,6 & 15,7 & 17,0 & 4,8 & 65,8 & 249,6 \\
\hline F değeri & $18,5 * *$ & 49,0 ** & $45,6^{* *}$ & $2603,1 * *$ & $99,7 * *$ & $410,0 * *$ & $6,2 * *$ & $1305,1 * *$ & $773,7 * *$ \\
\hline $\operatorname{LSD}(0,05)$ & 1,1 & 1,2 & 2,0 & 1,3 & 1,3 & 1,0 & 1,0 & 2,2 & 8,3 \\
\hline VK (\%) & 4,7 & 1,2 & 1,0 & 0,7 & 5,1 & 3,5 & 12,9 & 2,1 & 2,1 \\
\hline
\end{tabular}

** \%1 ihtimal seviyesinde önemli. Sütun içerisinde farkı harfle gösterilen ortalamalar arasında önemli fark $(\mathrm{P} \leq 0,05)$ vardır. ** is significant at $\% 1$ probability level. Mean values with the different letters in a column are significantly different at $\mathrm{P} \leq 0,05$.

§ CS: çıkıs süresi (days to emergence); CCS: çiçeklenme süresi (days to flowering); OS: olgunlaşma süresi (days to maturity); BB: bitki boyu (plant height); İBY: ilk bakla yüksekliği (first pod height); BBS: Bitkide bakla sayısı (number of pods per plant); BTS: baklada tane sayısı (number of seeds per pod); YTA: yüz tane ağırlı̆̆ı (hundred seed weight ); TV: tane verimi (seed yield) 


\section{Çıkış süresi (ÇS)}

Ekilen tohumun kısa sürede çimlenerek çıkış yapması çevre şartlarının yanında toplam çimlenme sıcaklık isteğine bağlıdır. Çimlenme için toplam sicaklık isteği yönünden fasulye genotipleri arasında önemli farkl11ıklar görülebilmekte ve düşük toplam sıcaklık isteğine sahip olanlar toprak sıcaklığının minimum çimlenme sicaklık isteğinin üzerinde olduğu durumlarda hızlı bir şekilde çimlenip kısa sürede çıkış yapabilmektedirler (Kantar ve Elkoca, 2001; Neto ve ark., 2006). Nitekim araştırmamızda da varyans analizi sonuçları çıkış süresi bakımından genotipik etkinin önemli olduğunu göstermiştir. Ortalama 13,9 gün olan çıkış süresi, genotiplere bağlı olarak 11 gün (kayıt no 4, 5, 6, 8, 9, 21) ile 17 gün (kayıt no 32) arasında değişim göstermiş ve 6 günlük bir varyasyon meydana gelmiştir (Çizelge 5). Yapılan diğer çalışmalarda da fasulyede çıkış süresinin genotiplere bağlı olarak Van ekolojik koşullarında 10-28,5 gün (Ekincialp ve Şensoy, 2013) ve 10,320,7 gün (Erdinç ve ark., 2013); Erzurum ekolojik koşullarında ise 13-16 gün arasında (Dumlu, 2009; Kantar ve ark., 2010) önemli değişim gösterdiği tespit edilmiştir.

\section{Çiçeklenme süresi (ÇÇS)}

Genotiplerin ortalama çiçeklenme süresi 58,2 gün olarak gerçekleşmiş ve çiçeklenme süresi bakımından genotipler arasındaki farkların çok önemli $(p \leq 0,01)$ olduğu belirlenmiştir (Çizelge 5). Genotiplerden 11 tanesi (kayıt no 1, 2, 3, 4, 12, 16, $23,24,33,34,35,39)$ en kısa çiçeklenme süresine (54 gün) sahip olurken, en uzun çiçeklenme süresi (62 gün) $6,7,13,14,15,41$ ve 49 no'lu genotiplerde tespit edilmiştir. Benzer şekilde farkl fasulye genotipleri ile yapılan diğer çalışmalarda da çiçeklenme süresinin Antalya ekolojik koşullarında 58-103 gün (Çanc1, 2016), Samsun ekolojik koşullarında 42-69 gün (Sözen ve ark., 2014), Bolu ekolojik koşullarında 43-75 gün (Yeken ve ark., 2019) ve Van ekolojik koşullarında ise 49,7-83,7 gün arasinda olmak üzere (Ekincialp ve Şensoy, 2013) genotiplere bağlı olarak önemli değişim gösterdiği rapor edilmiştir.

\section{Fizyolojik olum süresi (OS)}

Fasulyede olgunlaşma süresi genotip ve başta sıcaklık olmak üzere, çevre faktörleri tarafından belirlenmektedir (Dursun, 1999; Elkoca ve Çınar, 2015). Fasulye genotipleri arasında olgunlaşma için gerekli olan toplam sıcaklık isteği bakımından farklar bulunmakta; toplam sicaklık gereksinimi düşük olan genotipler daha erken, yüksek olan genotipler ise daha geç olgunlaşmaktadır (Ustaoğlu, 2008). Nitekim araştırmamıza ait varyans analizi sonuçları da genotiplerin olgunlaşma süresi üzerine önemli etkide bulunduğunu göstermiştir (Çizelge 5). Araştırmamızda ortalama fizyolojik olum süresi 128,7 gün olarak gerçekleşirken, genotiplerin fizyolojik olum süreleri 118,3 gün (kayıt no 39) ile 141 gün (kayıt no 49) arasında geniş bir aralıkta değişim göstermiştir. Fizyolojik olum süresi 118,3125 gün arasında değişen 13 genotip (kayıt no 1,2 , $3,12,16,21,23,24,31,33,34,35,39,42)$ erkencilik yönüyle dikkat çekici bulunmuştur. Diğer taraftan fizyolojik olum süresi 135-141 gün arasında değișen 7 genotipin (kayıt no 13, 14, 15, $40,41,45,49)$ ise oldukça geç'çi olduğu belirlenmiştir (Çizelge 5). Diğer araştırıcılar tarafindan farklı fasulye genotipleri kullanılarak değişik ekolojik koşullarda yürütülen çalışmalarda genotiplerin olgunlaşma süresi 99,2-120,0 gün (Pekşen, 2005), 85-149 gün (Çanc1, 2016) ve 95,0132,0 gün (Yeken ve ark., 2019) arasında değişim göstermiştir.

\section{Bitki boyu (BB)}

Fasulyede bitki boyu kalıtım derecesi yüksek $(\% 84,6-\% 90,0)$ bir karakterdir (Çiftçi ve Şehirali, 1984). Araştırmamızda da genotipik etkinin bitki boyu üzerinde çok önemli $(\mathrm{p} \leq 0,01)$ olduğu belirlenmiş ve genotiplerin bitki boyları $42,6 \mathrm{~cm}$ ile $156,7 \mathrm{~cm}$ arasında olmak üzere, çok geniş bir aralıkta değişim göstermiştir (Çizelge 5). En kısa bitki boyu bodur gelişme tipine sahip olan $18(42,6$ $\mathrm{cm}), 29(52,6 \mathrm{~cm})$ ve 34 no'lu genotiplerde $(61,3$ $\mathrm{cm})$ ölçülmüsşür. Bitki boyu, geri kalan yarı sarılıcı ve sarrlicı genotiplerde ise $78,4 \mathrm{~cm}$ (kayıt no 2) ile $156,7 \mathrm{~cm}$ (kayıt no 13) arasında yer almıştır (Çizelge 5). Özbekmez (2015) kullandığ genotiplerde bitki boyunun bodur tiplerde 28,4$50,5 \mathrm{~cm}$, sarılic1 tiplerde ise 97,6-197,8 cm arasında değiştiğini saptamıştır. Tamamı yarı sarılıcı karakterde olan İspir fasulye hatları ile çalışan Bıyıklı ve ark. (2021) ise bitki boyunun $85,1-112,3 \mathrm{~cm}$ arasında olmak üzere hatlar arasında önemli değişim gösterdiğini bildirmiştir. 
V. SOYDAS, M. AYDIN, E. ELKOCA, E. İLHAN: GÜMÜSSHANE İLI YEREL FASULYE GENOTIPLERININ MORFOLOJIK VE TARIMSAL ÖZELLIKLER YÖNÜNDEN KARAKTERIZASYONU ÜZERINE BIR ÖN ÇALIŞMA

Artvin ili yerel fasulye populasyonlarının tanımlamasını yapan Sözen (2006), bitki boyunun genotipik etkiye bağlı olarak 20-310 cm olmak üzere oldukça geniş bir varyasyona sahip olduğunu rapor etmiştir.

\section{İlk bakla yüksekliği (İBY)}

İlk bakla yüksekliği makinalı hasada uygunluğu belirleyen önemli parametrelerden biri olup, alt baklaları yüksekte olan genotipler makinayla hasat edilebilmektedir (Aydoğan ve ark., 2020). Araştırmamızda bu özellik bakımından genotipler arasındaki farkın çok önemli $(\mathrm{p} \leq 0,01)$ olduğu saptanmıştır (Çizelge 5). Ortalama ilk bakla yüksekliği $15,7 \mathrm{~cm}$ iken, genotiplere göre 6,7 ile $27,0 \mathrm{~cm}$ arasında değişim göstermiştir. En düşük ilk bakla yüksekliği $(6,7-9,9 \mathrm{~cm}) 6,16,23$ ve 24 no'lu genotiplerde ölçülmüştür. İlk bakla yüksekliği 22,6-27,0 cm arasında değişen 7 genotip (kayıt no 8, 15, 21, 22, 32, 36, 38) makinalı hasada uygunluk bakımından oldukça ümitvar bulunmuştur (Çizelge 5). Farklı fasulye genotipleri kullanılarak yürütülen diğer çalışmalarda da ilk bakla yüksekliğinin; 10,3-15,8 cm (Bozoğlu, 1995), 6,9-12,7 cm (Pekşen, 2005), 12,2-50,3 cm (Özbekmez, 2015) ve 8-25 cm (Yeken ve ark., 2019) olmak üzere genotipler arasında geniş bir aralıkta değişim gösterdiği saptanmıştır.

\section{Bitkide bakla sayısı (BBS)}

Varyans analizi sonuçları, bitkide bakla sayısı bakımından genotipler arasında çok önemli $(\mathrm{p} \leq 0,01)$ farkların bulunduğunu göstermiştir (Çizelge 5). Genotiplerin bitki başına bakla sayısı 9,2-49,6 adet olmak üzere oldukça geniş bir aralıkta değişim göstermiştir. Bitki başına en düşük bakla say1s1 (9,2-10,4 adet) $7,19,29,27$ ve 36 no'lu genotiplerde tespit edilmiştir. Diğer taraftan 17 (49,6 adet), 14 (32,7 adet), 18 (28,2 adet) ve 9 no'lu genotip (27,7 adet) bitki başına yüksek bakla sayısı değerleri ile oldukça dikkat çekici bulunmuşlardır (Çizelge 5). Farklı araştırıcılar tarafından yürütülen diğer çalışmalarda da bitki başına bakla sayısının genotipik etkiye bağlı olarak önemli değişim gösterdiği rapor edilmiştir (Zeytun, 1988; Pekşen, 2005; Sözen, 2006; Çanc1, 2016; Yeken ve ark., 2019).

\section{Baklada tane sayısı (BTS)}

Kalıtım derecesi yüksek bir karakter olan baklada tane sayıs1, en önemli verim unsurlarından biridir (Elkoca ve Kantar, 2004; Pekşen, 2005; Ceyhan ve ark., 2009). Araştırmamızda ortalama 4,8 adet olan baklada tane say1s1, genotiplere göre 3,1 ile 7,4 adet arasında değişim göstermiş ve genotipik etki çok önemli $(\mathrm{p} \leq 0,01)$ bulunmuştur (Çizelge 5). Genotiplerden 5 tanesi (kayit no 5, 18, 19, 23, 41) baklada en düşük tane sayısına (3,1-3,4 adet) sahip iken, en yüksek tane sayıs1 35 (6,1 adet), 21 (6,3 adet), 4 (6,9 adet) ve 7 no'lu genotipte (7,4 adet) belirlenmiştir (Çizelge 5). Fasulyede genotipik etkiye bağlı olarak bakladaki tane sayısının önemli seviyede değişim gösterdiği diğer araştırmacılar tarafından da teyit edilmiştir (Bozoğlu, 1995; Düzdemir, 1998; Varankaya, 2011; Özbekmez, 2015; Çanc1, 2016; Yeken ve ark., 2019).

\section{0 tane ağırlığı (YTA)}

Fasulyede önemli verim unsurlarından biri olan yüz tane ağırlığı, yüksek bir kalıtım derecesine sahiptir (Çiftçi ve Şehirali, 1984; Şehirali ve ark., 1994). Araştırmada kullandığımız genotiplerin yüz tane ağırlığ $23,4 \mathrm{~g}$ (kayıt no 20) ile 127,0 g (kayıt no 15) arasında değişmiş ve varyans analizi sonuçları genotipler arasındaki farkların çok önemli ( $\mathrm{p} \leq 0,01)$ olduğunu göstermiştir (Çizelge 5). Kuru fasulyede tane iriliği tüketici tercihlerini belirleyen en önemli kriterden biri olup tüketiciler çoğunlukla iri taneli çeşitleri tercih etmektedir (Çalışkan ve ark., 2018). Bu nedenle kaliteyi artırmaya yönelik pek çok ıslah programında tane iriliği üzerinde önemle durulmaktadır (Saba ve ark., 2016). Araştırmamızda en yüksek yüz tane ağırlığ́ (103,6-127,0 g) 5, 8, 15, 19, 27, 29 ve 43 no'lu genotiplerde belirlemiş ve bu genotipler oldukça ümitvar bulunmuşlardır. En düşük yüz tane ağırlığına ise 23,4-38,6 g arasında değişmek üzere $9,10,14,17,20,44,46,47,48$ ve 49 no'lu genotipler sahip olmuştur (Çizelge 5). Farklı fasulye genotipleri kullanılarak yürütülen diğer çalışmalarda da yüz tane ağırlığı 14,7-82,1 g (Çiftçi ve Şehirali, 1984), 22,2-125,3 g (Balkaya, 1999) ve 14,9-98,2 g (Erdinç ve ark., 2013) olmak üzere, genotiplere bağlı olarak oldukça geniş bir aralıkta değişim göstermiştir. 


\section{Tane verimi (TV)}

Araştırmamızda ortalama 249,6 $\mathrm{g} / \mathrm{m}^{2}$ olarak gerçekleşen tane verimi, genotiplere bağlı olarak 83,7-424 g/ $\mathrm{m}^{2}$ olmak üzere, geniș bir aralıkta değișim göstermiş ve tane verimi bakımından genotipik etki çok önemli $(p \leq 0,01)$ bulunmuştur (Çizelge 5). Genotiplerden 24 tanesi genel ortalamadan daha yüksek tane verimine sahip olurken, en düşük tane verimi $83,7-92,9 \mathrm{~g} / \mathrm{m}^{2}$ arasında değişmek üzere, 44, 47 ve 49 no'lu genotiplerde belirlenmiştir (Çizelge 5). En yüksek tane verimine ise $\left(424,0 \mathrm{~g} / \mathrm{m}^{2}\right) 4$ no'lu genotip sahip olmuş ve bunu azalan sıra ile $40(395,1$ $\left.\mathrm{g} / \mathrm{m}^{2}\right), 12\left(375,0 \mathrm{~g} / \mathrm{m}^{2}\right), 35\left(365,2 \mathrm{~g} / \mathrm{m}^{2}\right), 2(359,1 \mathrm{~g} /$ $\left.\mathrm{m}^{2}\right)$ ve 15 no'lu genotipler $\left(356,1 \mathrm{~g} / \mathrm{m}^{2}\right)$ izlemiştir. Kantitatif bir karakter olan ve çok sayıda gen tarafindan kontrol edilen tane veriminin (Yeken ve ark., 2019) genotipler arasinda önemli varyasyon gösterdiği diğer birçok çalışma sonucunda da ortaya koyulmuştur (Düzdemir ve Akdağ, 2001; Ülker ve Ceyhan, 2008; Varankaya, 2011; Elkoca ve Çınar, 2015).

\section{Fasulye Genotiplerinin Kümeleme Analizine Göre Gruplandırılması}

\section{Morfolojik özelliklere göre gruplandırma}

Gümüşhane yerel fasulye genotipleri, morfolojik varyabilitelerinin saptanmas1 amaciyla, 30 adet özellik bakımından kümeleme analizine tabi tutulmuş ve 3 grubun kümelendiği belirlenmiştir (Şekil 3 ve Çizelge 6).

Grup A: En kalabalık grup olup iki alt gruptan oluşmuştur. Toplam genotip sayıs1 23'tür (Şekil 3 ve Çizelge 6). Çiçek uzunluğu $17 \mathrm{~mm}$ ve üzerinde olan büyük çiçekli genotiplerin tamamı bu grupta kümelenmiştir. Orta yaprakçık uç şekli kısa olan 24 ve 30 no'lu genotip ile orta yaprakçığ küçük olan 23 no'lu genotip bu grupta yer almıștır. Ayrıca, bodur büyüme şekline sahip olan üç genotipten ikisi (kayit no 18 ve 34) de bu grupta kendine yer bulmuştur.

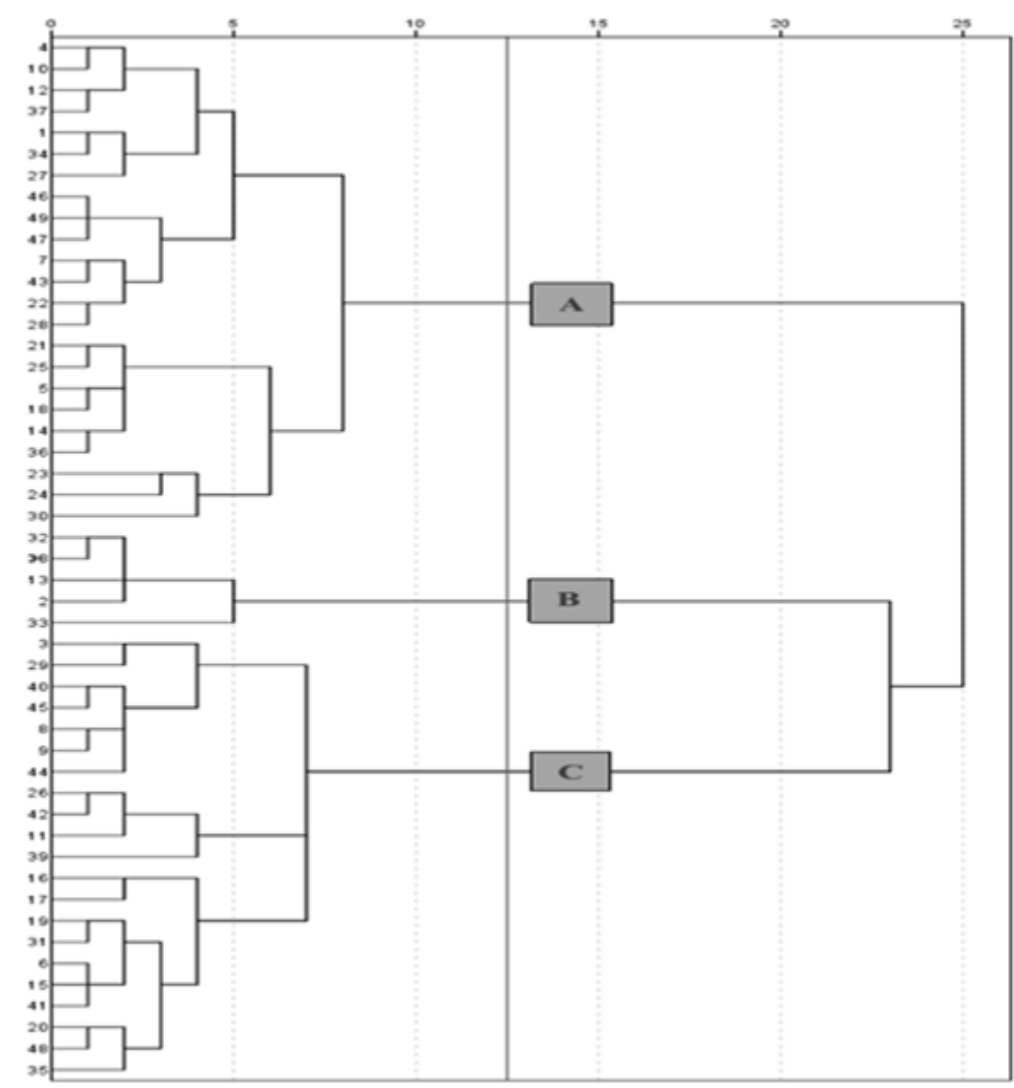

Şekil 3. Kümeleme analizinde morfolojik özelliklere ait dendogram.

Figure 3. Dendogram of cluster analysis based on morphological characteristics. 
Grup B: Tek alt grupta toplam 5 genotip içermektedir (Şekil 3 ve Çizelge 6). Kılçıklı olmayan genotiplerin tamam1 bu grupta kümelenmiştir. $\mathrm{Bu}$ grupta yer alan genotiplerin tamamında yaprak rengi orta yeşil, orta yaprakçık ucu orta uzunlukta ve brakte mızrak şeklindedir. Grup diğer yaprak ve çiçek özellikleri bakımından ise kendi içerisinde varyasyon göstermektedir.

Grup C: Üç alt grupta toplam 21 genotip içermektedir (Şekil 3 ve Çizelge 6). Brakte şekli orta olan 5 genotipten 4'ü bu grupta bulunmaktadır. Çiçek uzunlukları 11-15 mm arasında değişim göstermekte ve çiçek boyutu küçük olan 5 genotipten 4'ü yine bu grupta yer almaktadır. Grup; çiçek sap uzunluğu bakımından ise geniş bir varyasyon göstermekte olup, çiçek sap uzunluğu en k1sa (kayit no 29) ve en uzun olan (kayit no 39) genotipleri içermektedir.

\section{Tarımsal özelliklere göre gruplandırma}

Tarımsal özellikler yönünden varyabilitelerinin saptanması amacıyla Gümüşhane yerel fasulye genotipleri 9 adet özellik bakımından kümeleme analizine tabi tutulmuş ve 4 grubun kümelendiği belirlenmiştir (Şekil 4 ve Çizelge 7).

Grup A: Toplam genotip sayıs1 16 olan iki adet alt gruptan oluşmaktadır (Şekil 4 ve Çizelge 7). Bitki boyu $(107,2 \mathrm{~cm})$, ilk bakla yüksekliği $(14,2 \mathrm{~cm})$ ve bakladaki tane sayısı (4,5 adet) bakımından en sonda yer almaktadır. Bitkide bakla sayısı (19,3 adet) bakımından ilk sirada yer alan bu grup, 100 tane ağırlığ $(69,4 \mathrm{~g})$ ve ortalama tane verimi $\left(253,8 \mathrm{~g} / \mathrm{m}^{2}\right)$ bakımından ise kendine ikinci sırada yer bulmuştur (Çizelge 8).
Grup B: İki alt grupta toplam 17 genotip içermektedir (Şekil 4 ve Çizelge 7). Çıkış $(12,9$ gün), çiçeklenme (56,7gün) ve olgunlaşma süresi (127,0 gün) bakımından en erkenci olan bu grup, baklada tane sayısı (5,1 adet), 100 tane ağırlı̆̆ $(82,7 \mathrm{~g})$ ve ortalama tane verimi $\left(333,5 \mathrm{~g} / \mathrm{m}^{2}\right)$ bakımından ilk sırada yer almaktadır (Çizelge 8).

Grup C: Tek bir alt grupta 4 genotiple temsil edilmektedir (Şekil 4 ve Çizelge 7). Çıkış $(15,0$ gün), çiçeklenme (59,8 gün) ve olgunlaşma süresi (131,3 gün) bakımından en geçci olan bu grup, bitkide bakla sayısı (14,2 adet), 100 tane ağırlığ1 $(26,4 \mathrm{~g})$ ve tane verimi $\left(92,9 \mathrm{~g} / \mathrm{m}^{2}\right)$ bakımından son sırada yer almaktadır (Çizelge 8).

Grup D: İki alt grupta 12 genotiple temsil edilmektedir (Şekil 4 ve Çizelge 7). En yüksek bitki boyuna $(129,8 \mathrm{~cm})$ sahip olan bu grup, Grup $C$ 'den sonra en düşük bakla sayısı (14,4 adet), 100 tane ağırlı̆̆ $(50,2 \mathrm{~g})$ ve tane verimine $(177,5 \mathrm{~g} /$ $\mathrm{m}^{2}$ ) sahiptir (Çizelge 8).

Kümeleme analizine ait bu sonuçlar kümeleme analizinin genotipleri başarılı bir şekilde sınıflandırdığını, bu nedenle ıslah ve çeşit geliştirme çalışmalarına aktarılacak materyallerin seçilmesinde başarıyla kullanılabileceğini göstermiştir. Diğer araştırıcılar tarafından da kümeleme analizinin ümitvar genotiplerin seleksiyonuna yönelik önemli ipuçları verdiğine dair çok sayıda araştırma sonucu rapor edilmiştir (Ergün, 2005; Madakbaş ve ark., 2006; Sözen, 2006:, Ceyhan ve ark., 2009; Kahraman ve ark., 2014).

Çizelge 6. Morfolojik özelliklere göre kümeleme analizinde oluşan grup ve alt gruplar.

Table 6. Group and subgroups in the cluster analysis based on morphological characteristics.

\begin{tabular}{lllc}
\hline Grup (Group) & Alt grup (Subgroup) & Genotip (Genotype) & Say1 (Number) \\
\hline A & 1 & $4,10,12,37,1,34,27,46,49,47,7,43,22,28$ & 14 \\
& 2 & $21,25,5,18,14,36,23,24,30$ & 9 \\
& & & 23 \\
\hline B & Toplam (Total) & $32,38,13,2,33$ & 5 \\
& 1 & $3,29,40,45,8,9,44$ & 5 \\
\hline C & 1 & $26,42,11,39$ & 7 \\
& 2 & $16,17,19,31,6,15,41,20,48,35$ & 4 \\
& & 10 \\
& & 21 \\
\hline
\end{tabular}




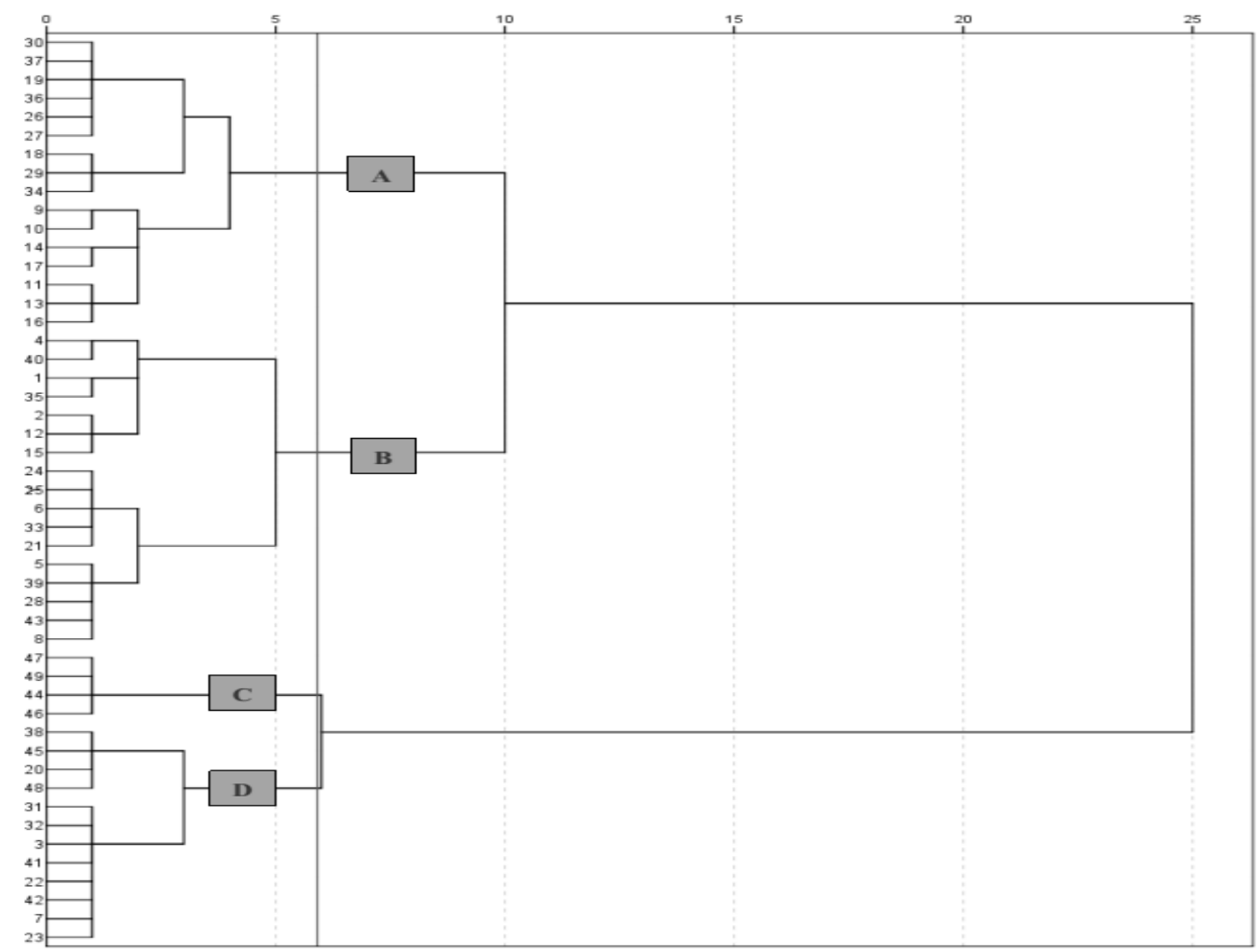

Şekil 4. Kümeleme analizinde tarımsal özelliklere ait dendogram.

Figure 4. Dendogram of cluster analysis based on agricultural characteristics.

Çizelge 7. Tarımsal özelliklere göre kümeleme analizinde oluşan grup ve alt gruplar.

Table 7. Group and subgroups in the cluster analysis based on agricultural characteristics.

\begin{tabular}{lllc}
\hline Grup (Group) & Alt grup (Subgroup) & Genotip (Genotype) & Say1 (Number) \\
\hline A & 1 & $30,37,19,36,26,27,18,29,34$ & 9 \\
& 2 & $9,10,14,17,11,13,16$ & 7 \\
& Toplam (Total) & & 16 \\
\hline B & 1 & $4,40,1,35,2,12,15$ & 7 \\
& 2 & $24,25,6,33,21,5,39,28,43,8$ & 10 \\
& Toplam (Total) & & 17 \\
\hline C & 1 & $47,49,44,46$ & 4 \\
& Toplam (Total) & $38,45,20,48$ & 4 \\
\hline D & 1 & $31,32,3,41,22,42,7,23$ & 4 \\
& 2 & 12 \\
\hline Genel toplam (Grand total) & & 49
\end{tabular}

Çizelge 8. Tarımsal özelliklere göre kümeleme analizinde oluşan gruplara ait ortalama değerler.

Table 8. Average values of the groups formed in cluster analysis based on agricultural characteristics.

\begin{tabular}{lccccccccc}
$\begin{array}{l}\text { Gruplar } \\
\text { Groups }\end{array}$ & $\begin{array}{c}\text { § ÇS (gün) } \\
\text { (day) }\end{array}$ & $\begin{array}{c}\text { ÇÇS (gün) } \\
\text { (day) }\end{array}$ & $\begin{array}{c}\text { OS (gün) } \\
\text { (day) }\end{array}$ & BB (cm) & $\begin{array}{c}\text { IBY } \\
(\mathrm{cm})\end{array}$ & $\begin{array}{c}\text { BBS (adet) } \\
(\text { nu. })\end{array}$ & $\begin{array}{c}\text { BTS (adet) } \\
(\text { nu. })\end{array}$ & $\begin{array}{c}\text { YTA } \\
(\mathrm{g})\end{array}$ & $\begin{array}{c}\text { TV } \\
\left(\mathrm{g} / \mathrm{m}^{2}\right)\end{array}$ \\
\hline A & 14,1 & 59,3 & 129,6 & 107,2 & 14,2 & 19,3 & 4,5 & 69,4 & 253,8 \\
B & 12,9 & 56,7 & 127,0 & 115,4 & 16,6 & 16,2 & 5,1 & 82,7 & 333,5 \\
C & 15,0 & 59,8 & 131,3 & 108,6 & 15,4 & 14,4 & 5,1 & 26,4 & 92,9 \\
D & 14,6 & 58,3 & 129,0 & 129,5 & 16,4 & 15,8 & 4,8 & 50,2 & 177,5 \\
\hline
\end{tabular}

§ ÇS: çıkış süresi (days to emergence); ÇÇS: çiçeklenme süresi (days to flowering); OS: olgunlaşma süresi (days to maturity); BB: bitki boyu (plant height); İBY: ilk bakla yüksekliği (first pod height); BBS: Bitkide bakla sayısı (number of pods per plant); BTS: baklada tane sayısı (number of seeds per pod); YTA: yüz tane ağırlı̆̆ı (hundred seed weight ); TV: tane verimi (seed yield). 


\section{SONUÇ}

Fasulye, ülkemizin hemen hemen her bölgesinde yetiştirilmektedir. Gerek yetiştiriciliği yapılan yerlerde uzun yıllar boyunca üreticiler tarafindan yapılan seleksiyonlar ve gerekse ülkemizin sahip olduğu ekolojik koşullardaki çeşitlilik, fasulye genotipleri üzerinde etkili olmuş ve zaman içerisinde farklı yerel genotiplerin ortaya çıkmasını sağlamıştır. Birer hazine niteliğinde olan bu yerel genotiplerin toplanarak tanımlamalarının yapılması; 1slah çalışmalarına aktarılabilecek, temel özellikleri bilinen materyallerin elde edilmesi açısından büyük önem taşımaktadır. $\mathrm{Bu}$ amaca yönelik olarak yürütülen bu çalışmada, Gümüşhane ilinden toplanan 49 yerel fasulye genotipinin morfolojik ve tarımsal özellikler yönünden karakterizasyonu yapılmıştır. Araştırma sonuçları, 1slah çalışmalarına materyal sağlama bakımından Gümüşhane'nin önemli fasulye gen kaynaklarına sahip olduğunu ortaya koymuştur.

Morfolojik karakterizasyona ait gözlemler genotiplerin büyüme şekli, yaprak, çiçek ve bakla özellikleri bakımından önemli varyasyona sahip olduğunu göstermiştir. Tane özellikleri bakımından ise genotipler benzerlik göstermiş; bir kısmında dairesel, diğer bir kısmında ise dairesel-eliptik olmak üzere, genotiplerin tamamında tanenin şeker tipinde olduğu saptanmıştır. Ülkemizde şeker tane tipi piyasada oldukça rağbet görmekte ve şeker tane tipine sahip tescilli kuru fasulye çeşitlerine ihtiyaç duyulmaktadır. Çalışma bu açıdan değerlendirildiğinde, üzerinde çalıştı̆̆ımız bu fasulye genotiplerinin şeker tane tipindeki kuru fasulye çeşit geliştirme çalışmalarına ıslah materyali olarak önemli katkı sağlayacağı öngörülmektedir.

Baklanın kılçıklı yapıda olması fasulyenin taze olarak tüketimini olumsuz yönde etkilemekte, bu nedenle taze fasulye islahında kılçıksız genotipler büyük önem taşımaktadır. Araştırmamızda 5 genotipin kılçıksız olduğu belirlenmiş ve bu genotipler morfolojik özellikler dikkate alınarak yapılan sınıflandırmada Grup B'de kümelenmiştir. $\mathrm{Bu}$ grubu taze fasulye 1slah çalışmalarında değerlendirmenin yararlı olacağı düşünülmektedir.

Ülkemizin vejetasyon periyodu dar olan bazı yörelerinde, fasulyenin soğuk ve don zararına uğramadan gelişebileceği dönem oldukça kısadır. Kısa sürede çıkış yapan, kısa sürede çiçeklenen ve sonbahar ilk donlarından önce olgunlaşan erkenci çeşitlerin geliştirilmesi, bu tip yörelerde fasulye tarımındaki riskleri en aza indirmektedir. Araştırmamızda tarımsal özelliklere göre yapılan sınıflandirmada en erkenci ve en yüksek verimli genotipler Grup B'de, en geçci ve en düşük verimli genotipler ise Grup C'de kümelenmiştir. Bu sonuç, erkencilik ve tane veriminin genotiplerin ayırılmasında önemli rol oynadığını göstermiştir. Erkenci ve yüksek verimli çeşit geliştirmeye yönelik yapılacak ıslah çalışmalarında Grup B'den seçim yapılması başarı şansını artıracaktır. $\mathrm{Bu}$ bağlamda, Grup B'de yer alan genotiplerin sonraki ürün yıllarında hem tarla şartlarında verim ve verim unsurları hem de laboratuvarda tane kalite parametreleri yönünden değerlendirilmesi ve böylece tarla koşullarında üstün özelliklerini devam ettiren teknolojik özellikleri yüksek genotiplerin çeşit geliştirme çalışmalarına aktarılması uygun olacaktır. İleriki çalışmalarda genotiplerin moleküler karakterizasyonlarının da yapılması, ıslah çalışmalarına aktarılan genotipler hakkında çok daha kapsamlı veri setinin elde edilmesine önemli katkı sağlayacaktır.

\section{TEŞEKKÜR}

Bu çalışma, yüksek lisans tezinden üretilmiş olup, yazarlar katkılarından dolayı Gümüşhane İl Tarım ve Orman Müdürlüğü ve İlçe Müdürlüklerine teşekkür ederler. 


\section{LITERATÜR LISTESI}

Açıkgöz, N. 2004. Bitki 1slahı, bitki genetik kaynakları, introdüksiyonlar, varyasyon oluşturma, melezleme ve ebeveyn seçimi. Ege Tarımsal Araştırma Enstitüsü Müdürlüğü. Yayın No: 114. İzmir.

Anonim. 2001. Tarımsal Değerleri Ölçme Denemeleri Teknik Talimatı. Yemeklik Tane Baklagiller. T.C. Tarım ve Köyişleri Bakanlığ 1 Koruma ve Kontrol Genel Müdürlüğü. Tohumluk Tescil ve Sertifikasyon Merkezi Müdürlüğü. Ankara.

Anonim. 2019a. Türkiye İstatistik Kurumu (TUIK) http://www.tuik.gov.tr/Start.do (Erişim tarihi: 20/09/2019).

Anonim. 2019b. http://cografyaharita.com/turkiye mulki idare_haritalari3.html (Erişim Tarihi:20/09/2019).

Anonim. 2019c. https://parselsorgu.tkgm.gov.tr/ (Erişim Tarihi:20/09/2019).

Anonymous. 2019 Food and Agriculture Organization of the United Nations (FAOSTAT) http://www.fao.org/faostat/en/\#data (Erişim Tarihi:20/09/2019).

Aydın, A. ve Y. Sezen. 1995. Toprak Kimyası Laboratuvar Kitab1. Atatürk Üniversitesi Ziraat Fakültesi Ders Yayınları No: 174. Erzurum.

Aydoğan, C., E. Elkoca, K. Haliloğlu ve M. Aydın. 2020. Bazı İspir kuru fasulye (Phaseolus vulgaris L.) hatlarının seleksiyonu üzerine bir ön çalışma. ANADOLU J. of AARI 30 (2): 251-265.

Balkaya, A. 1999. Karadeniz bölgesindeki taze fasulye (Phaseolus vulgaris L.) gen kaynaklarının toplanmas1, fenolojik ve morfolojik özelliklerinin belirlenmesi ve taze tüketime uygun tiplerin teksel seleksiyon yöntemi ile seçimi üzerinde araştırmalar. Doktora tezi. Ondokuz Mayıs Üniversitesi Fen Bilimleri Enstitüsü Samsun.

Bıyıklı, B., E. Elkoca ve M. Aydın. 2021. İspir kuru fasulye (Phaseolus vulgaris L.) popülasyonunun karakterizasyonu ve seleksiyon yoluyla islahı. Anadolu Tarım Bilimleri Dergisi 36: 20-33.

Bliss, F.A. 1980. Common bean. pp. 273-284. In: W.R. Fehr and H.H. Hadley (Eds.). Hybridization of Crop Plants. American Society of Agronomy-Crop Science Society of America, Madison, Wisconsin, USA.

Bode, D., F. Elezi, and B. Gixhari. 2013. Morphological characterisation and interrelationships among descriptors in Phaseolus vulgaris accessions. Agriculture and Forestry/Poljoprivreda i Sumarstvo 59 (2): $175-185$.

Bozoğlu, H. 1995. Kuru fasulyede (Phaseolus vulgaris L.) bazı tarımsal özelliklerin genotip $\mathrm{x}$ çevre interaksiyonu ve kalitım derecelerinin belirlenmesi üzerine bir araştırma. Doktora tezi. Ondokuz Mayıs Üniversitesi Fen Bilimleri Enstitüsü Samsun.
Ceyhan, E., M. Önder ve A. Kahraman. 2009. Fasulye genotiplerinin bazı tarımsal özelliklerinin belirlenmesi. Selçuk Üniversitesi Selçuk Tarım ve Gıda Bilimleri Dergisi 23 (49): 67-73.

Çalışkan, S., R. İ. Aytekin, A. K. Yağız ve C. Yavuz. 2018. Bazı fasulye (Phaseolus vulgaris L.) çeşitlerinde tam ve kısıtlı sulama uygulamalarının tane kalitesi üzerine etkisi. Türk Tarım - Gıda Bilim ve Teknoloji Dergisi 6 (12): 1853-1859.

Çanc1, H. 2016. Fasulye (Phaseolus spp. L.) mini-öz koleksiyonunun Antalya koşullarında fenolojik, morfolojik ve tarımsal özelliklerinin belirlenmesi. Tarım Bilimleri Araştırma Dergisi 9 (2): 26-32.

Çiftçi, C. Y. ve S. Şehirali. 1984. Fasulye (Phaseolus vulgaris L.) çeşitlerinde değişik özelliklerin fenotipik ve genotipik farklılıkların saptanması. Ankara Üniversitesi Fen Bilimleri Enstitüsü Yayın No: TB 4. Ankara.

Dumlu, B. 2009. Kuzey Doğu Anadolu Bölgesinden toplanan 23 fasulye (Phaseolus vulgaris L.) genotipinin fenolojik ve morfolojik karakterizasyonu. Yüksek lisans tezi. Atatürk Üniversitesi Fen Bilimleri Enstitüsü Erzurum.

Dursun, A. 1999. Erzincan'da yaygın olarak yetiştirilen yalanc1 dermason fasulye (Phaseolus vulgaris L.) popülasyonunun seleksiyon yoluyla islahı. Doktora tezi. Atatürk Üniversitesi Fen Bilimleri Enstitüsü Erzurum.

Düzdemir, O. 1998. Kuru fasulye (Phaseolus vulgaris L.) genotiplerinde verim ve diğer bazı özellikler üzerine bir araştırma. Yüksek lisans tezi. Gaziosmanpaşa Üniversitesi Fen Bilimleri Enstitüsü Tokat.

Düzdemir, O. ve C. Akdağ. 2001. Türkiye kuru fasulye (Phaseolus vulgaris L,) gen kaynaklarının karakterizasyonu: II. Verim ve diğer bazı özellikleri. Gaziosmanpaşa Üniversitesi Ziraat Fakültesi Dergisi 18 (1): 101-105.

Ekincialp, A. ve S. Şensoy. 2013. Van Gölü havzası fasulye genotiplerinin bazı bitkisel özelliklerinin belirlenmesi. Yüzüncü Yıl Üniversitesi Tarım Bilimleri Dergisi 23 (2): 102-111.

Elkoca, E. ve F. Kantar. 2004. Erzurum ekolojik koşullarına uygun erkenci ve yüksek verimli kuru fasulye (Phaseolus vulgaris L.) genotiplerinin belirlenmesi. Atatürk Üniversitesi Ziraat Fakültesi Dergisi 35 (3-4): 137-142.

Elkoca, E. ve T. Çınar. 2015. Bazı kuru fasulye (Phaseolus vulgaris L.) çeşit ve hatlarının Erzurum ekolojik koşullarına adaptasyonu, tarımsal ve kalite özellikleri. Anadolu Tarım Bilimleri Dergisi 30: 141-153.

Erdinç, Ç., Ö. Türkmen ve S. Şensoy. 2013. Türkiye'nin bazı fasulye genotiplerinin çeşitli bitkisel özelliklerinin belirlenmesi. Yüzüncü Y1l Üniversitesi Tarım Bilimleri Dergisi 23 (2): 112-125. 
Ergün, A. 2005. Samsun ilindeki barbunya fasulye gen kaynaklarının karakterizasyonu ve morfolojik varyabilitesinin belirlenmesi üzerine bir araştırma. Yüksek lisans tezi. Ondokuz Mayıs Üniversitesi Fen Bilimleri Enstitüsü Samsun.

Fita, A., A. Rodríguez-Burruezo, M. Boscaiu, J. Prohens, and O. Vicente. 2015. Breeding and domesticating crops adapted to drought and salinity: a new paradigm for increasing food production. Frontiers in Plant Science 6: 1-14.

Hofer, J. M. I., C. W. Gourlay, and T. H. N. Ellis. 2001. Genetic control of leaf morphology: a partial view. Annals of Botany 88: 1129-1139.

IBM Corp. Released 2016. IBM SPSS Statistics for Windows, Version 24.0. Armonk, NY: IBM Corp.

Kahraman, A., M. Önder, and E. Ceyhan. 2014. Cluster analysis in common bean genotypes (Phaseolus vulgaris L.). Turkish Journal of Agricultural and Natural Sciences Special Issue 1: 1030-1035.

Kantar, F. ve E. Elkoca. 2001. Bazı fasulye (Phaseolus vulgaris L.) çeşitlerinin kardinal ve toplam sıcaklık isteklerinin belirlenmesi. Türkiye 4. Tarla Bitkileri Kongresi. 17-21 Eylül 2001. Cilt I Tahıllar ve Yemeklik Tane Baklagiller. Tekirdağ. s. 371-375.

Kantar, F., E. Elkoca, C. Eken ve M. F. Dönmez. 2010. Kuzey Doğu Anadolu Bölgesi ve Çoruh Vadisi'nde yetiştirilen kuru fasulye gen kaynaklarının toplanması ve değerlendirilmesi. TUBİTAK TOVAG 1070400 No.lu Proje Sonuç Raporu. Ankara.

Karataş, A., D. T. Büyükdinç, A. İpek, M. Yağcığlu, K. Sönmez ve Ş. Ş. Ellialtığlu. 2017. Türkiye'de fasulyede yapilan morfolojik ve moleküler karakterizasyon çalışmaları. Türk Bilimsel Derlemeler Dergisi 10 (1): 16-27.

Kessler, S., and N. Sinha. 2004. Shaping up: the genetic control of leaf shape. Current Opinion in Plant Biology 7: 65-72.

Madakbaş, S. Y., H. Özçelik ve M. Ergin. 2006. Çarşamba Ovası'nda bodur taze fasulye popülasyonlarından belirlenmiş olan hatlar arasındaki farklılıkların belirlenmesi. Harran Üniversitesi Ziraat Fakültesi Dergisi 10 (3/4): 71-77.

Madakbaş, S.Y., and M. Ergin. 2011. Morphological and phenological characterization of Turkish bean (Phaseolus vulgaris L.) genotypes and their present variation states. African Journal of Agricultural Research 6 (28): 6155-6166.

Martins, S. R., F. J. Vences, L. S. de Miera, M. R. Barroso, and V. Carnide. 2006. RAPD analysis of genetic diversity among and within Portuguese landraces of common white bean (Phaseolus vulgaris L.). Scientia Horticulturae 108 (2): 133-142.

Neto, N. B. M., M. R. Prioli, A. B. Gatti, and V. J. M. Cardoso. 2006. Temperature effects on seed germination in races of common beans (Phaseolus vulgaris L.). Acta Scientiarum. Agronomy 28 (2): 155-164.
Özbekmez, Y. 2015. Ordu ekolojik koşullarında bazı kuru fasulye (Phaseolus vulgaris L.) çeşit ve genotiplerinin verim, verim öğeleri ile tohum ve teknolojik özelliklerinin belirlenmesi. Yüksek lisans tezi. Ordu Üniversitesi Fen Bilimleri Enstitüsü Ordu.

Pekşen, E. 2005. Samsun koşullarında bazı fasulye (Phaseolus vulgaris L.) genotiplerinin tane verimi ve verimle ilgili özellikler bakımından karşılaştırılması. Ondokuz Mayıs Üniversitesi Ziraat Fakültesi Dergisi 20 (3): 88-95.

Saba, I., P. A. Sofi, N. A. Zeerak, M. A. Bhat, and R. R. Mir. 2016. Characterisation of a core set of common bean (Phaseolus vulgaris L.) germplasm for seed quality traits. SABRAO Journal of Breeding and Genetics 48 (3): 359-376.

Sözen, Ö. 2006. Artvin ili yerel fasulye (Phaseolus vulgaris L.) popülasyonlarının toplanması, tanımlanması ve morfolojik varyabilitesinin belirlenmesi. Yüksek lisans tezi. Ondokuz Mayıs Üniversitesi Fen Bilimleri Enstitüsü Samsun.

Sözen, Ö., H. Özçelik ve H. Bozoğlu. 2014. Doğu Karadeniz Bölgesi yerel fasulye (Phaseolus vulgaris L.) popülasyonlarının karakterizasyonu ve morfolojik değişkenliğin ortaya konulması. Biyoloji Bilimleri Araştırma Dergisi 7 (1): 29-36.

Stoilova, T., G. Pereira, and M. de Sousa. 2013. Morphological characterization of a small common bean (Phaseolus vulgaris L.) collection under different environments. Journal of Central European Agriculture 14 (3): 854-865.

Şehirali, S., H. Özçelik ve Ö. Yorgancılar. 1994. Kuru tane olarak tüketilen bodur fasulye gen kaynaklarının karakterizasyonu üzerinde araştırma. Türkiye 1. Tarla Bitkileri Kongresi. 25-29 Nisan 1994. Cilt 2 Bitki Islahı Bildirileri. İzmir. s. 134-140.

Şehirali, S., M. Özgen, A. Karagöz, M. Sürek, S. Adak, İ. Güvenç ve D. Kenar. 2005. Bitki genetik kaynaklarının korunma ve kullanımı. TMMOB Ziraat Mühendisleri Odası VI. Teknik Kongresi. Ankara.

Ustaoğlu, Y.N. 2008. Tescilli kuru fasulye (Phaseolus vulgaris L.) çeşitlerinde çeşitli fenolojik dönemler için toplam sicaklık isteklerinin belirlenmesi. Yüksek lisans tezi. Atatürk Üniversitesi Fen Bilimleri Enstitüsü Erzurum.

Ülker, M. ve E. Ceyhan. 2008. Orta Anadolu ekolojik şartlarında yetiştirilen fasulye (Phaseolus vulgaris L.) genotiplerinin bazı tarımsal özelliklerinin belirlenmesi. Selçuk Üniversitesi Ziraat Fakültesi Dergisi 22 (46): 77-89.

Varankaya, S. 2011. Yozgat ekolojik şartlarında yetiştirilen fasulye (Phaseolus vulgaris L.) genotiplerinin bazı tarımsal özelliklerinin belirlenmesi. Yüksek lisans tezi. Selçuk Üniversitesi Fen Bilimleri Enstitüsü Konya.

Ward, J. H. 1963. Hierarchical grouping to optimize an objective function. Journal of the American Statistical Association 58: 236-244. 
ANADOLU 31 (2) 2021

Yeken, M. Z., V. Çiftçi, H. Çancı, G. Özer ve F. Kantar, F. 2019. Türkiye'nin Batı Anadolu Bölgesi'nden toplanan yerel fasulye genotiplerinin morfolojik karakterizasyonu. Uluslararası Tarım ve Yaban Hayatı Bilimleri Dergisi 5 (1): 124-139.

Zeytun, A. 1988. Çarşamba Ovasında yetiştirilen fasulye çeşitlerinin fenolojik ve morfolojik karakterlerinin belirlenmesi üzerine bir araştırma. Yüksek lisans tezi. Ondokuz Mayıs Üniversitesi Fen Bilimleri Enstitüsü Samsun. 